\title{
Change of Baiu Rain Band in Global Warming Projection by an Atmospheric General Circulation Model with a 20-km Grid Size
}

\author{
Shoji KUSUNOKI, Jun YOSHIMURA, Hiromasa YOSHIMURA, Akira NODA \\ Climate Research Department, Meteorological Research Institute, Japan Meteorological Agency, \\ Tsukuba, Japan
}

Kazuyoshi OOUCHI and Ryo MIZUTA

Advanced Earth Science and Technology Organization, Tsukuba, Japan

(Manuscript received 27 April 2005, in final form 23 March 2006)

\begin{abstract}
A global warming projection experiment was conducted on the Earth Simulator using a very high horizontal resolution atmospheric general circulation model, with $20-\mathrm{km}$ grid size (the 20 -km model). Such high horizontal resolution in a global climate model is unprecedented for a global warming projection. Experiments using the $20-\mathrm{km}$ model were conducted by adopting the time-slice method, in which future changes in sea surface temperature (SST) were predicted by an atmosphere-ocean general circulation model (AOGCM) called MRI-CGCM2.3. The A1B emission scenario, proposed by the Intergovernmental Panel on Climate Change (IPCC), was assumed in the experiment.

The model reproduces a realistic Baiu rain band under the present-day climate conditions in terms of geographical distribution and northward seasonal march. Experiments of the dependency of the horizontal resolution on the reproducibility of the Baiu rain band have revealed that the $20-\mathrm{km}$ model generally exhibits higher performance than a model with a lower horizontal resolution. The future climate simulation shows that precipitation, and its intensity increases over the Yangtze River valley of China, the East China Sea, Western Japan, and the ocean to the south of the Japan archipelago. Conversely, precipitation and its intensity decrease over the Korean peninsula and Northern Japan. The termination of the Baiu season tends to be delayed until August.

The future precipitation change is mainly attributable to the change in the horizontal transport of water vapor flux and its convergence associated with the intensification of a subtropical high. This can be interpreted as an atmospheric response to the El Niño condition of the ocean. The change in the wind field mainly contributes to the change in the water vapor flux in the case of the Baiu rain band.
\end{abstract}

\section{Introduction}

The rainy season, or rain band, observed in an East Asia summer monsoon season is called the Baiu in Japan, the Mei-yu in China and the

Corresponding author: Shoji Kusunoki, Climate Research Department, Meteorological Research Institute, Japan Meteorological Agency, 1-1, Nagamine, Tsukuba, Ibaraki 305-0052, Japan.

E-mail: skusunok@mri-jma.go.jp

(C) 2006, Meteorological Society of Japan
Changma in Korea. This rainy season begins nearly simultaneously with the onset of the summer monsoon over central India in early June. During this rainy season, the rain band, or rain front, stagnates over the Yangtze River valley, with its eastern edge passing through the Japan Islands (Ninomiya and Akiyama 1992). The rain band migrates northward with seasonal march, and the rainy season terminates in mid-July (Wang and Ho 2002). Hereafter, we consistently use the terminology "the 
Baiu rain band" to denote this rain band or associated frontal structure extending over East Asia in the summer monsoon season. We also consistently use the terminology "the Baiu season" to denote the period in which the Baiu rain band prevails. The onset and withdrawal of the Baiu season depends on the location (Wang and Ho 2002). The variability of the Baiu rain band, or the Baiu season, greatly affects the life and society of people living in East Asia. Therefore, a change in the Baiu rain band in a warmer future climate is one of the main concerns for this region.

Many atmospheric general circulation model (AGCM) studies have attempted to reproduce the Baiu rain band by forcing models with observed or climatological sea surface temperature (SST). However, the models have commonly underestimated the rainfall amount (Lau et al. 1996; Lau and Yang 1996; IPCC 2001; Liang et al. 2001; Kusunoki et al. 2001). Moreover, they have failed to simulate the observed northward migration of the Baiu rain band (Kang et al. 2002). Research on the dependence of the horizontal resolution on the reproducibility of the Baiu rain band has yielded optimistic results, namely, that models with a higher horizontal resolution increase the rainfall amount of the Baiu rain band, while models with a lower horizontal resolution do not. Nevertheless, not even the highest-resolution simulation can realistically simulate the Baiu rain band (Sperber et al. 1996; Kawatani and Takahashi 2003; Kobayashi and Sugi 2004).

Many projections have been conducted to investigate the change of the East Asian summer monsoon in a future warmer climate. The main results are summarized in Table 1 . Preceding studies generally agree on an increase of precipitation. Hume et al. (1994) to Min et al. (2004) have evaluated the changes of surface temperature and precipitation based on areaaveraged statistics over East Asia, because atmospheric models have insufficient horizontal resolution to resolve local change. Recent studies with higher resolution atmospheric models (Kitoh et al. 2005; Kitoh and Uchiyama 2006; Kimoto 2005; Kimoto et al. 2005) have made it possible to discuss the local change of climate over East Asia, although the resolution remains insufficient to properly reproduce the Baiu rain band.
An observational study (Ninomiya and Akiyama 1992) stressed the fact that disturbances of the multi-scales, from the mesoscale to synoptic and planetary scales, play important roles in the formation and maintenance of the Baiu rain band, and that the Baiu rain band is characterized by mutual interactions between phenomena within this multi-scale hierarchical system. Namely, the Baiu rain band consists of disturbances with a horizontal scale ranging from about $10 \mathrm{~km}$ of a meso- $\gamma$ structure, about $100 \mathrm{~km}$ of a meso- $\beta$ structure, about $1000 \mathrm{~km}$ of a meso- $\alpha$ structure, to about $5000 \mathrm{~km}$ of a synoptic and planetary scale structure. This suggests that the difficulty in simulating the Baiu rain band by AGCM is still attributable to an insufficient horizontal resolution. Hence, the purpose of this study is to evaluate the ability of a high resolution $20-\mathrm{km}$ mesh AGCM to simulate the present-day climatology of the Baiu rain band, and to project its change in a warmer climate. Hereafter, the 20$\mathrm{km}$-mesh AGCM is refereed to as the " $20-\mathrm{km}$ model".

Section 2 contains a brief description of the model. Section 3 presents the experimental design. Section 4 explains the verification data used. Section 5 evaluates the reproducibility of the Baiu rain band in the present-day climate simulations, with the $20-\mathrm{km}$ model in comparison with simulations by coarser horizontal resolution models. Section 6 reports the change of the Baiu rain band in global warming projection. Section 7 is an interpretation of the change of the Baiu rain band as an atmospheric response to changes in sea surface temperature (SST) change. The relative contribution of change in the wind field, and the water vapor to a horizontal water vapor flux is estimated qualitatively. Finally, Section 8 summarizes the results.

\section{The models}

High horizontal resolution AGCM experiments were conducted by adopting the "timeslice" method (Bengtsson et al. 1996; IPCC 2001 ), which is a two-tier global warming projection approach, using an atmosphere-ocean general circulation model (AOGCM), and an AGCM with a horizontal resolution that is higher than that of the atmospheric part of the AOGCM. 
Table 1. Projected change of East Asian summer monsoon by preceding global warming studies with AOGCMs.

\begin{tabular}{|c|c|c|c|c|c|}
\hline Authors & Year & Model & $\begin{array}{l}\text { Horizontal } \\
\text { spacing of } \\
\text { atmosphere }\end{array}$ & Emission scenario & Results \\
\hline Hulme et al. & 1994 & 7 AOGCMs & $300-900 \mathrm{~km}$ & $2 \mathrm{xCO} 2$ & Precipitation increases \\
\hline IPCC & 1996 & 9 AOGCMs & $270-540 \mathrm{~km}$ & $2 \mathrm{xCO} 2$ & Precipitation increases \\
\hline Kitoh et al. & 1997 & MRI-CGCM1 & $500 \mathrm{~km}$ & $2 \mathrm{xCO} 2,4 \mathrm{xCO} 2$ & $\begin{array}{l}\text { The subtropical high } \\
\text { intensifies and extends } \\
\text { westward }\end{array}$ \\
\hline Giorgi et al. & 2000 & 5 AOGCMs & $300-600 \mathrm{~km}$ & $2 \mathrm{xCO} 2$ & $\begin{array}{l}\text { No change in precipitation } \\
\text { with CO2 only, No consensus } \\
\text { if aerosol included }\end{array}$ \\
\hline Giorgi et al. & 2001 & 9 AOGCMs & $270-540 \mathrm{~km}$ & IPCC SRES A2, B2 & $\begin{array}{l}5 \%-20 \% \text { precipitation } \\
\text { increase }\end{array}$ \\
\hline IPCC & 2001 & & & & $\begin{array}{l}\text { Same as Giorgi et al. (2000, } \\
2001)\end{array}$ \\
\hline $\begin{array}{l}\text { Lal and } \\
\text { Harasawa }\end{array}$ & 2001 & 4 AOGCMs & $270-540 \mathrm{~km}$ & No description & Precipitation increases \\
\hline Hu et al. & 2003 & 16 AOGCM & $270-540 \mathrm{~km}$ & $2 \mathrm{xCO} 2$ & $\begin{array}{l}\text { Precipitation increases } \\
\text { over China }\end{array}$ \\
\hline Min et al. & 2004 & 7 AOGCMs & $270-540 \mathrm{~km}$ & IPCC SRES A2, B2 & Precipitation increases \\
\hline Kitoh et al. & 2005 & MRI-CGCM2 & $270 \mathrm{~km}$ & IPCC SRES A2, B2 & $\begin{array}{l}\text { Precipitation increases in } \\
\text { South China and decreases in } \\
\text { North China, The subtropical } \\
\text { high intensifies and extends } \\
\text { westward }\end{array}$ \\
\hline Kimoto & 2005 & $\begin{array}{l}\text { MIROC and } \\
17 \text { AOGCMs }\end{array}$ & $110-270 \mathrm{~km}$ & $\begin{array}{l}\text { IPCC SRES A1B } \\
\text { for MIROC, } 2 \mathrm{xCO} 2 \\
\text { for } 17 \mathrm{AOGCMs}\end{array}$ & $\begin{array}{l}\text { Precipitation increases with } \\
\text { the strenthening of the } \\
\text { subtropical and the Okhotsk } \\
\text { highs }\end{array}$ \\
\hline Kimoto et al. & 2005 & MIROC & $110 \mathrm{~km}$ & IPCC SRES A1B & $\begin{array}{l}\text { Precipitation and intensity } \\
\text { increases }\end{array}$ \\
\hline Kitoh & 2006 & & & & $\begin{array}{l}\text { Review "Asian monsoon in the } \\
\text { future" in the book The Asain } \\
\text { Monsoon }\end{array}$ \\
\hline $\begin{array}{l}\text { Kitoh and } \\
\text { Uchiyama }\end{array}$ & 2006 & 7 AOGCMs & $270 \mathrm{~km}$ & IPCC SRES A1B & $\begin{array}{l}\text { Baiu rainy season withdrawal } \\
\text { delays around Japan }\end{array}$ \\
\hline
\end{tabular}

AOGCM: Atmosphere-Ocean General Circulation Model

IPCC: Intergovernmental Panel on Climate Change

MRI-CGCM: Meterorological Research Institute-Coupled General Circulation Model, Japan

SRES: Special Report on Emissions Scenarios

MIROC: Name of the AOGCM developed cooperatively by the University of Tokyo, National Institute for Environmental Studies and Frontier Research Center for Global Change, Japan 
The AOGCM used in the first step of the time-slice experiment is an MRI-CGCM2.3 (Yukimoto et al. 2006a). The atmospheric part of this model has a horizontal spectral truncation of T42, corresponding to an approximately 270$\mathrm{km}$ horizontal grid spacing, and 30 levels with a $0.4 \mathrm{hPa}$ top. The oceanic part of this model is the Bryan-Cox-type grid model. The horizontal grid spacing is 2.5 degrees in longitude and 2 degrees in latitude. In order to resolve the equatorial Kelvin and Rossby waves, the latitudinal grid spacing is decreased near the equator between $4^{\circ} \mathrm{S}$ and $4^{\circ} \mathrm{N}$ down to the minimum of 0.5 degree at the equator. In the sea ice model, compactness and thickness are predicted on the base of thermodynamics. The sea ice is advected by the surface ocean current. To keep the model climatology close to the observation, a flux adjustment technique was applied to the heat and freshwater globally, and to the wind stress near the equator.

The $20-\mathrm{km}$ model used in the second step of the time-slice experiment is a model jointly developed by the Japan Meteorological Agency (JMA), and the Meteorological Research Institute (MRI). The model is based on an operational numerical weather prediction model used at JMA, with some modifications in radiation and land surface processes as a climate model at MRI (Mizuta et al. 2006). The time integration was accelerated by introducing a semi-Lagrangian three-dimensional advection scheme (Yoshimura and Matsumura 2005). The time step was 6 minutes. The model has a horizontal spectral truncation of TL959, corresponding to about a $20-\mathrm{km}$ horizontal grid spacing, and has 60 levels with a $0.1 \mathrm{hPa}$ (altitude of about $65 \mathrm{~km}$ ) top. TL959 means that the model has a spectral Triangular truncation of spherical function at wave number 959, with a Linear grid for wave-to-grid transformation. The model has 1920 grids in longitude, and 960 grids in latitude. A mere increase in the horizontal resolution was found to gives rise to large model biases in precipitation and temperature, much less organization of convection, and suppression of tropical cyclone generation. Therefore, we carefully tuned the model to improve the model's present-day climatology by changing the parameters in the evaporation process, cloud water content diagnosis, vertical transport of horizontal momentum in cumulus, and gravity wave drag (Mizuta et al. 2006). The integration of the $20-\mathrm{km}$ model and data processing were performed on the Earth Simulator (Habata et al. 2003; Habata et al. 2004).

\section{Experimental design}

The time-slice experiment was conducted as follows. The $20-\mathrm{km}$ model was integrated for ten years as a time-slice, present-day climate simulation, with observed climatological SSTs (Reynolds and Smith 1994) averaged for 12 years from 1982 to 1993 . The general performance of the simulation is discussed in detail by Mizuta et al. (2006). As a time-slice, future climate simulation, the AGCM was integrated for ten years with projected SSTs, by the MRICGCM2.3. The projected SSTs used for the future experiment were a superposition of the observed SSTs and the differences between the present SSTs (1979-1998, 20-year mean taken from $20^{\text {th }}$-Century climate simulations) and the future SSTs (2080-2099, 20-year mean), which were obtained from a climate change simulation (Yukimoto et al. 2006) with the MRI-CGCM2.3. SST distributions for June and July, corresponding to the Baiu season are depicted in Fig. 1. The spatial structure of the SST change by the MRI-CGCM2.3 simulation, resembles an El Niño-like response in which warming is larger in the tropical central and eastern Pacific than in the western Pacific (Figs. 1e, f). The SSTs include seasonal cycle, but they do not include interannual variations. The absence of SST interannual variations may lead to an underestimation of the interannual variability of the atmospheric response.

The Intergovernmental Panel on Climate Change (IPCC) SRES A1B emission scenario (IPCC 2000) was assumed for future climate simulations. The A1B scenario is an intermediate emission scenario characterized by a future world of very rapid economic growth, global population that peaks in the middle of the 21 st Century and declines thereafter, and by a balanced introduction of new and more efficient technologies of all energy supply (IPCC 2000; IPCC 2001). From around 2080 to 2099, with the concentration of $\mathrm{CO}_{2}$ nearly doubled relative to that at the end of 20th Century, the global mean surface air temperature increases by about 2.5 degrees for the MRI-CGCM2.3 simulation (Yukimoto et al. 2006b). The concen- 

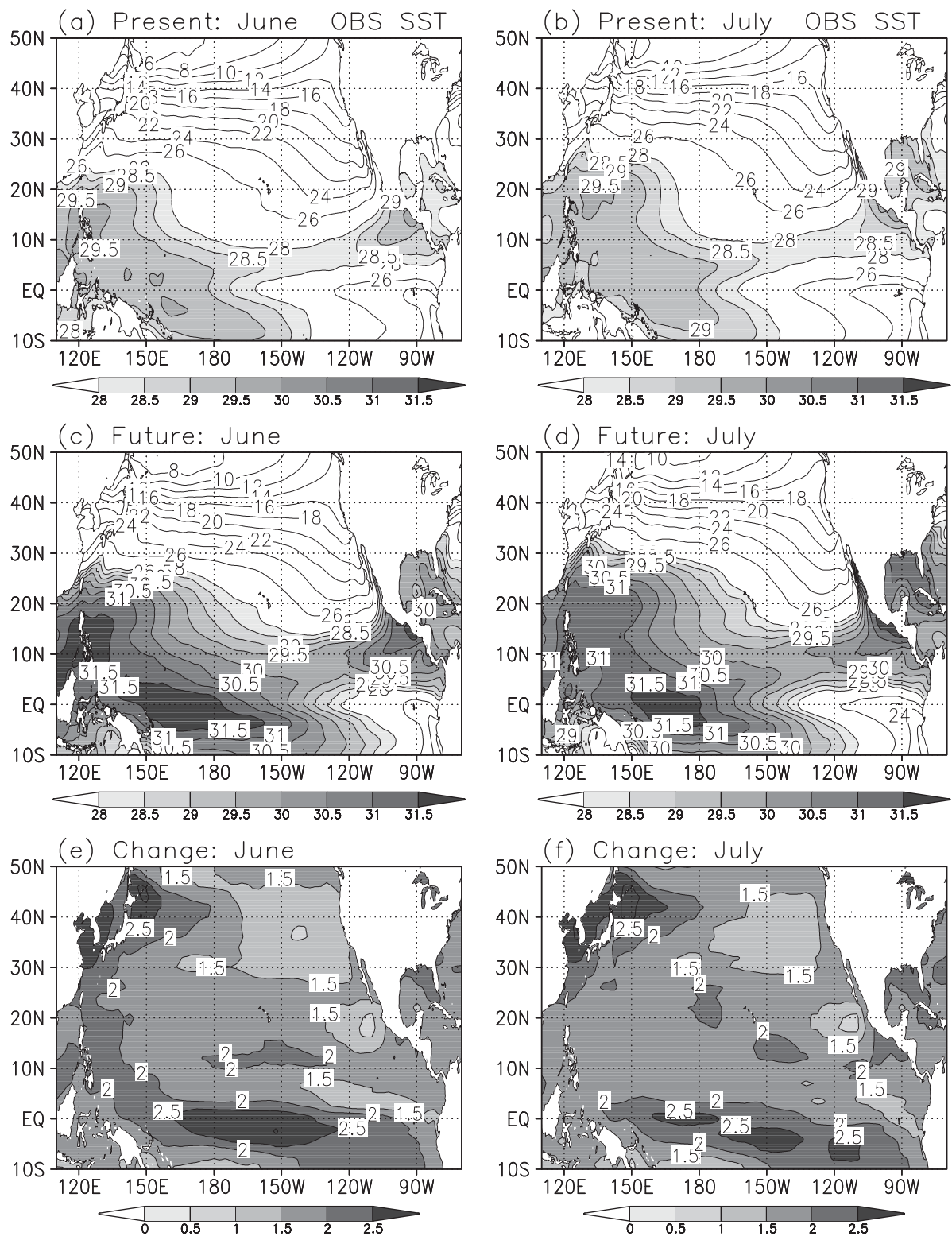

Fig. 1. Sea surface temperature (SST)s given to the $20 \mathrm{~km}$ model. (a) Climatological SST for the June present-day simulation. The observed SST by Reynolds and Smith (1994) are averaged for 12 years from 1982 to 1993 . The contour interval is $0.5^{\circ} \mathrm{C}$ above $27^{\circ} \mathrm{C}$ and $2.0^{\circ} \mathrm{C}$ otherwise. (b) Same as (a) but for July. (c) Same as (a), but for the future simulation. Superposition of the observed SSTs (a) and the SST change (e). (d) Same as (c), but for July. (e) Change of the SST for June projected by the Atmosphere-Ocean General Circulation Model (AOGCM) 'MRI-CGCM2.3' with the IPCC SRES scenario A1B (IPCC 2000). The 20-year mean from 2080 to 2099 relative to the 20-year mean from 1979 to 1998 is shown. The base period is taken from the climate of the 20th Century experiment. The ensemble size of both experiments is five. The contour interval is $0.5^{\circ} \mathrm{C}$. 
trations of greenhouse gas and aerosols in the $20-\mathrm{km}$ model were assumed as those for the year 2090 prescribed by the A1B scenario.

\section{Verification data}

To verify the precipitation climatology in the present-day climate simulation, observational data of the Global Precipitation Climatology Project (GPCP), compiled by Adler et al. (2003) are used. The horizontal resolution is 2.5 degree in longitude and latitude, corresponding to a grid spacing of about $210 \mathrm{~km}$ over Japan. The data cover the 23 years from 1979 to 2001 . This period includes the 12 years from 1983 to 1994, to construct the observed climatological SST given to the present climate simulations.

In addition to the conventional GPCP 2.5degree data widely used to verify the climate models, we have used two other source of higher horizontal resolution precipitation data. One is the one-degree daily data of GPCP compiled by Huffman et al. (2001). Horizontal resolution is one degree in longitude and latitude, corresponding to a grid spacing of about $90 \mathrm{~km}$ over Japan. These data are more appropriate to evaluate the small-scale structure of the $20-\mathrm{km}$ model than conventional 2.5-degree resolution data, although the data cover only 7 years from 1997 to 2003.

The other is the Radar-Automated Meteorological Data Acquisition System (AMeDAS) data, which is precipitation data covering the Japan Islands and their coastal regions. It is estimated from observations of radars calibrated by densely distributed AMeDAS rain gauges (about 17-km mesh). The calibration algorithm is described in Makihara (1996). The spatial resolution is approximately $5 \mathrm{~km}$. The data cover only 10 years from 1991 to 2000 . Both the one-degree daily data of GPCP, and the Radar-AMeDAS data, are useful to validate the small horizontal structure of the 20$\mathrm{km}$ model, although neither source of data includes the entire 12-year period from 1983 to 1994 of observed SST used for the present climate simulations.

Observations based on the ERA-40 data (Simmons and Gibson 2000) are used to verify the model climatology of the mean sea level pressure (MSLP) and the water vapor flux, and to make a composite map of the water vapor flux for the El Niño years. The horizontal reso- lution is 2.5 degrees in longitude and latitude. The data cover the period from 1958 to 2001.

\section{Present-day climate simulations}

\subsection{Precipitation}

The first step of the global warming projection is to examine the model's ability to reproduce the present-day climatology. The validity of the Baiu rain band climatology in the present-day simulation by the $20-\mathrm{km}$ model is evaluated in this subsection. To examine the resolution dependence of the results, we also performed simulations with three lower spatial resolutions using the same model framework (Mizuta et al. 2006). The resolutions are TL63L40 (128 grids in longitude, 64 grids in latitude, about $270 \mathrm{~km}$ in grid size, and 40 vertical levels up to $0.4 \mathrm{hPa})$, TL95L40 (192, 96 grids, $180 \mathrm{~km}$ ), and TL159L40 (320, 160 grids, $110 \mathrm{~km}$ ). In these additional simulations, the parameter adjustments introduced to the 20$\mathrm{km}$ model (TL959L60, 1920, 960 grids, 60 vertical levels up to $0.1 \mathrm{hPa}$ ) were not included, but the modification on the vertical transport of the horizontal momentum was included. The time steps are 30 minutes in all the three lower resolutions, while that of the $20-\mathrm{km}$ model is 6 minutes.

Figure 2 compares the observed climatological precipitation of June with simulations by the models under the present-day climate condition. Coarser models ( $b-d)$ tend to underestimate precipitation over Japan and the Korean peninsula. In contrast, the $20-\mathrm{km}$ model (e) more accurately reproduces the concentration of precipitation over western Japan and the Korean peninsula, although the rainfall of the 20 $\mathrm{km}$ model is rather excessive in comparison with the observations (a). A similar tendency was found in the July case (Fig. 3).

In order to quantify the performance of the $20-\mathrm{km}$ model more objectively and rigorously, we introduced the "Taylor diagram" proposed by Taylor (2001) which is widely used in the evaluation of a climate model performance. See the Appendix for details. The root-mean-square (RMS) difference between the observation and model can be decomposed into the bias and the centered pattern RMS difference. Figure $4 a$ shows the RMS differences and biases of models for the June precipitation climatology. The target domain is the same as that shown 

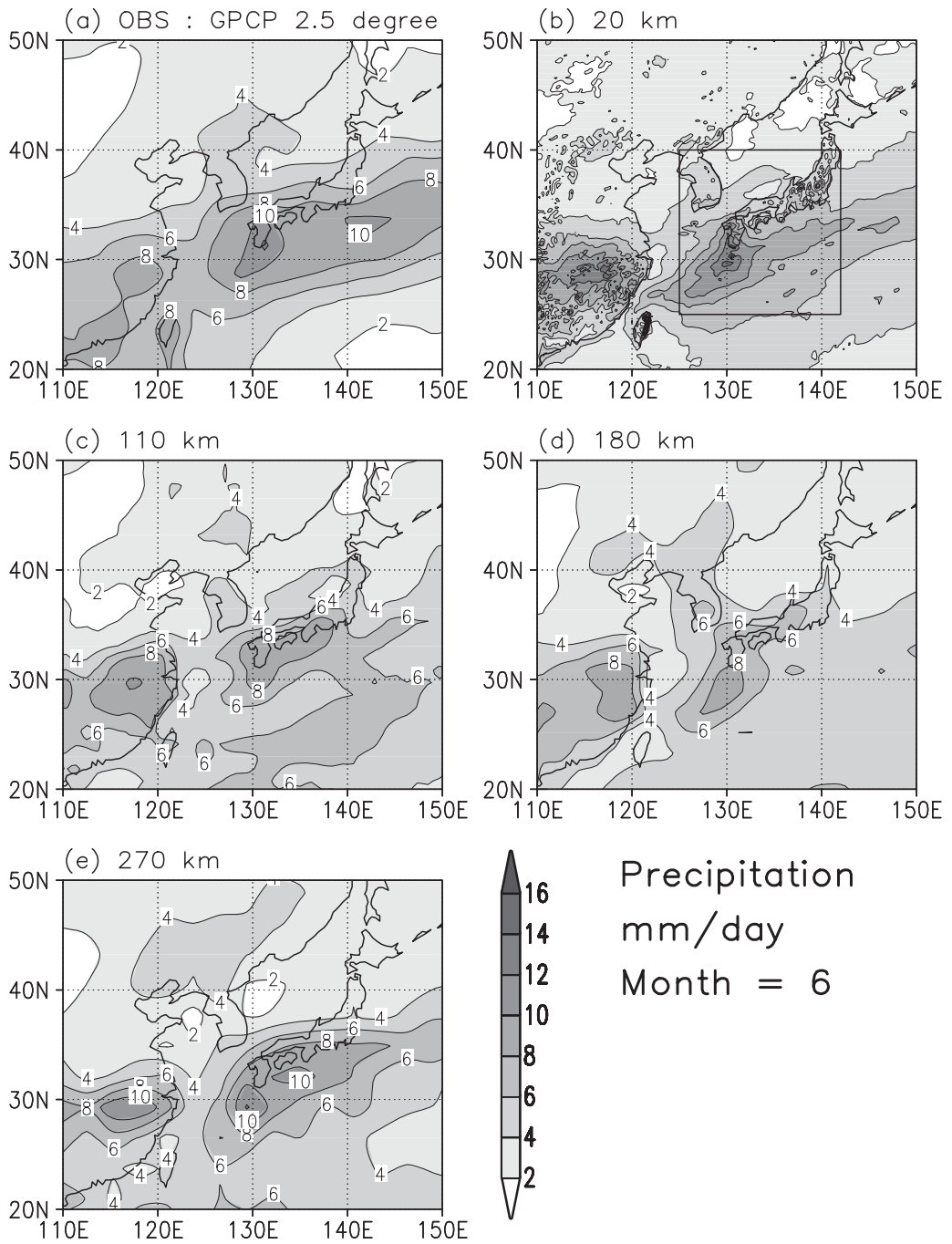

Precipitation $\mathrm{mm} /$ day

Month $=6$

Fig. 2. Observed and simulated climatological precipitation of June. The contour interval is $2 \mathrm{~mm} /$ day. (a) Observation based on Global Precipitation Climatology Project (GPCP, Adler et al. 2003) data averaged for 12 years from 1982 to 1993. The average period is identical to that of the observed climatological SSTs given to the models. The horizontal resolution is 2.5 degrees in longitude and latitude, which corresponds to about $210 \mathrm{~km}$ at $35^{\circ} \mathrm{N}$. The box shows the target region for the time series analyses in Figs. 8, 10, 18 and 19. (b) Model climatology of 20-km horizontal resolution (TL959). Contour labels are omitted for legibility. (c) $110 \mathrm{~km}$ (TL159). (d) $180 \mathrm{~km}$ (TL095). (e) $270 \mathrm{~km}$ (TL063). The integration time is 10 years for all models with the same observed climatological SST. Numbers after "TL" denote the triangular truncation wave number of spherical harmonics in the model, where a larger number means higher horizontal resolution.

in Fig. 2. The $20-\mathrm{km}$ model has a smaller or equivalent RMS difference and bias than the lower resolution models.

The centered pattern RMS difference can be regarded as a bias-corrected RMS difference. The Taylor diagram displays a geometric relationship among the centered pattern RMS dif- ference, the observed standard deviation, the simulated standard deviation, and the spatial correlation coefficient. Figure $4 \mathrm{~b}$ is the Taylor diagram for the June precipitation climatology. The $20-\mathrm{km}$ model has a larger, or equivalent correlation coefficient than the lower resolution models. When skill $S$ is used for evaluating 

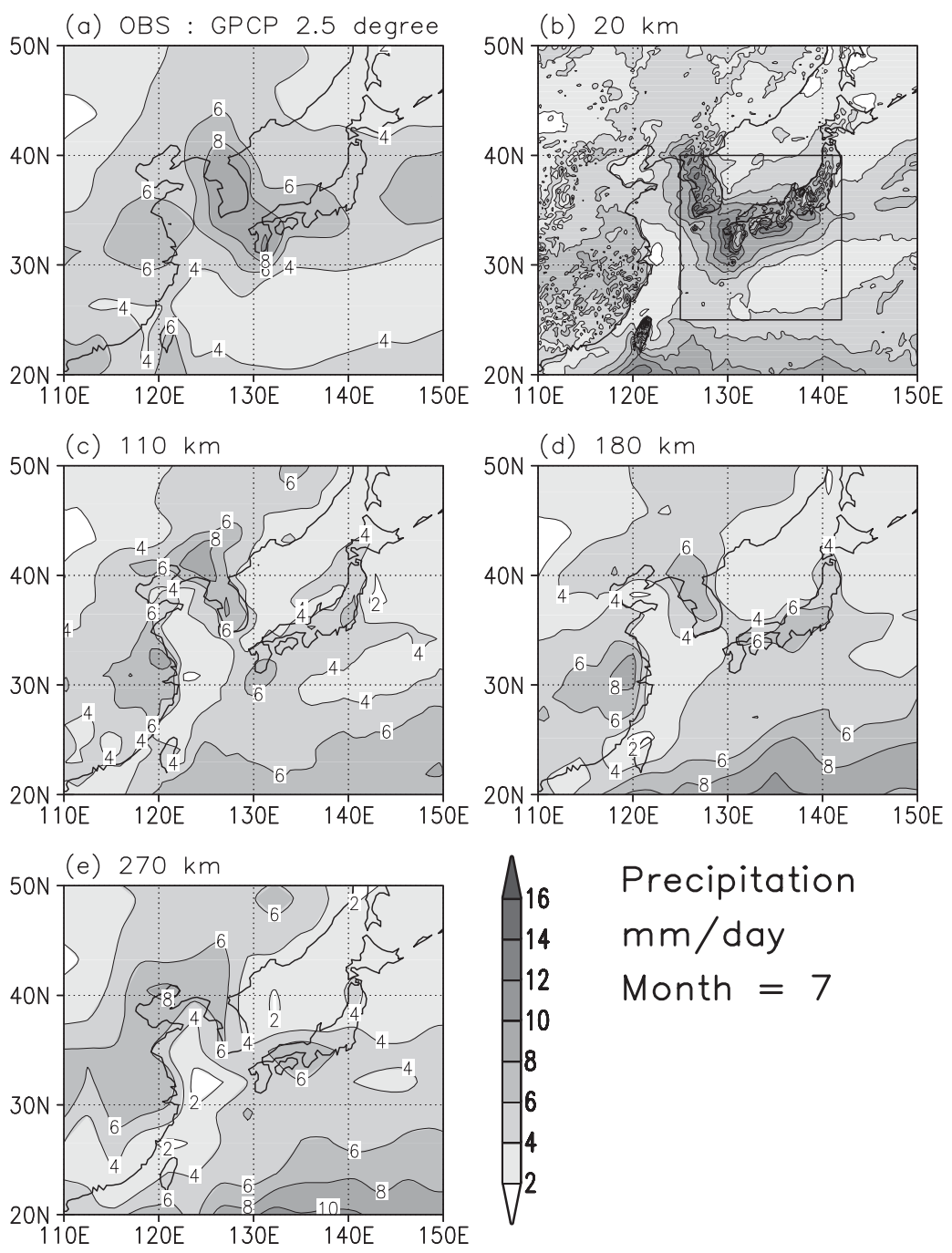

Fig. 3. Same as Fig. 2, but for July.

both the standard deviation and the correlation coefficient, the $20-\mathrm{km}$ model has the highest accuracy. For July, same statistics are depicted in Fig. 5. The $20-\mathrm{km}$ model has the smallest RMS difference, but it has large positive bias as is indicated by the excessive precipitation in Fig. $3 \mathrm{~b}$. In contrast, the Taylor diagram of Fig. $5 \mathrm{~b}$ suggests the evident advantage of the $20-\mathrm{km}$ model in terms of the correlation coefficient and Skill $S$.

To evaluate the small horizontal structure of the $20-\mathrm{km}$ model, the GPCP one-degree daily precipitation dataset (about a $90-\mathrm{km}$ grid spacing at $35^{\circ} \mathrm{N}$ ), and the Radar-AMeDAS data $(5 \mathrm{~km})$ are compared with the simulation ob- tained with the $20-\mathrm{km}$ model in Fig. 6. In June, the $20-\mathrm{km}$ model accurately simulates the location of the Baiu rain band extending over the Kyushu Island $\left(129-132^{\circ} \mathrm{E}, 31-34^{\circ} \mathrm{N}\right)$ and over the ocean to the south of Japan, although the rainfall amount is underestimated compared with that in the Radar-AMeDAS data (c). The $20-\mathrm{km}$ model also reproduces orographic rain over Honshu (the largest Japan island). The tendency in July is similar to that found in June. The July precipitation of the GPCP one-degree daily precipitation (b) seems to be underestimated compared to that in the Radar-AMeDAS data (d). This could be attributed to the difference in observation period 
Precipitation Climatology Lon $=110-150 \mathrm{E} \quad$ Lat $=20-50 \mathrm{~N}$ Month $=6$ OBS: GPCP 2.5

(a) RMSE and Bias

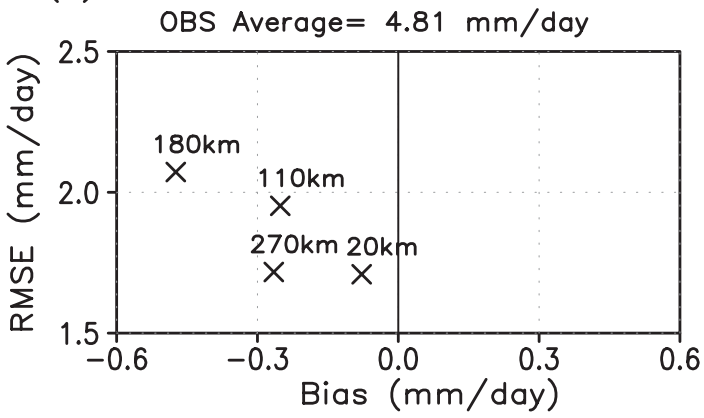

(b) Taylor diagram

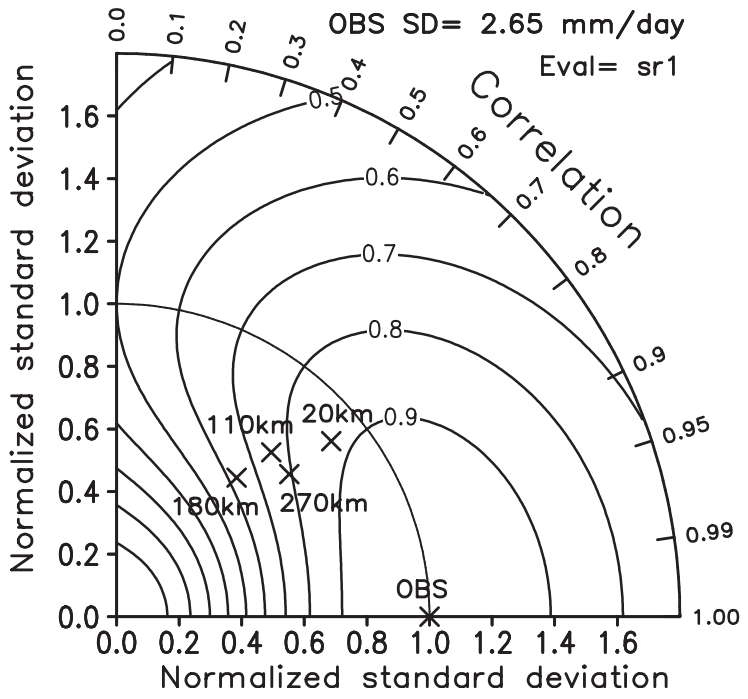

Fig. 4. Skill dependence of geographical distribution of precipitation on the horizontal resolution $(\mathrm{km})$ of models for June. The verification data is GPCP data (Fig. 2a), and the target domain is the same as in Fig. $2\left(110-150^{\circ} \mathrm{E}, 20\right.$ $50^{\circ} \mathrm{N}$ ). (a) Root mean square error (RMSE)s and biases. The unit is $\mathrm{mm} /$ day. The domain average of observation is shown above the panel. (b) Taylor diagram for displaying pattern statistics (Taylor 2001). The radial distance from the origin is proportional to the standard deviation of a simulated pattern normalized by the observed standard deviation. The correlation coefficient between the observed and simulated fields is given by the azimuthal position. The contour shows the measure of
Precipitation Climatology Lon $=110-150 \mathrm{E} \quad$ Lat $=20-50 \mathrm{~N}$ Month $=7$ OBS: GPCP 2.5

(a) RMSE and Bias

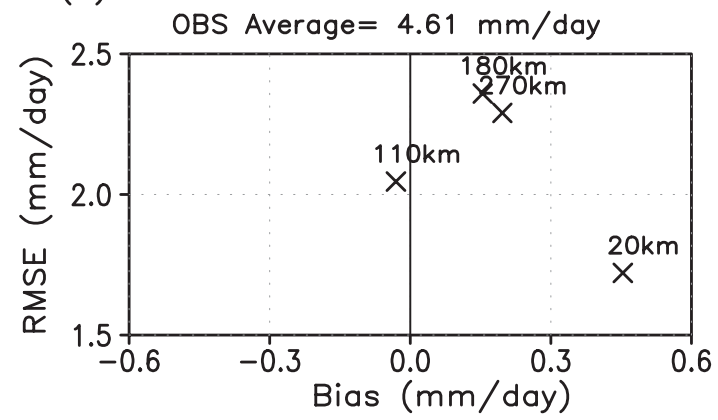

(b) Taylor diagram

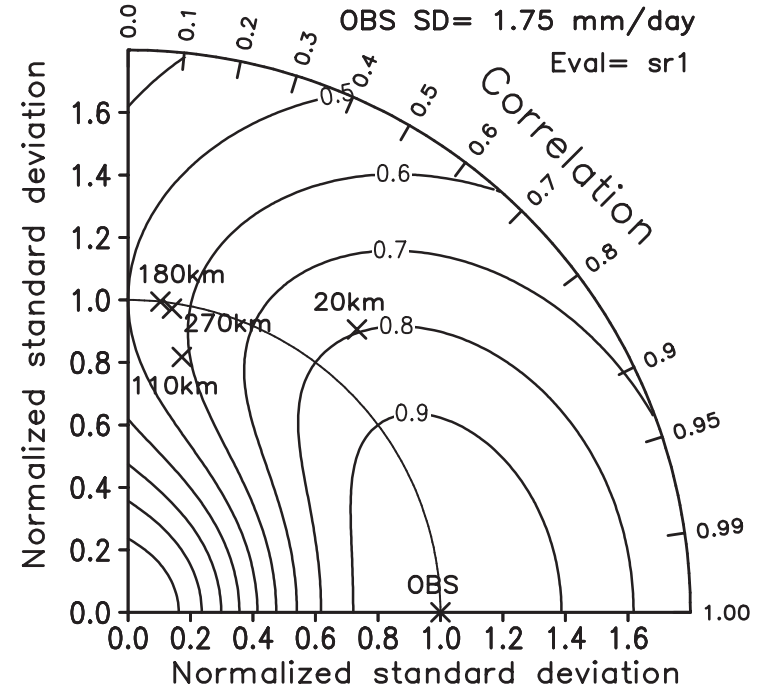

Fig. 5. Same as Fig. 4, but for July.

skill " $S$ " evaluating both the standard deviation and correlation coefficient. $S$ approaches unity in case of a perfect simulation (position of OBS in the panel). The standard deviation of the observation in the domain is shown above the panel. See Appendix for technical details. 

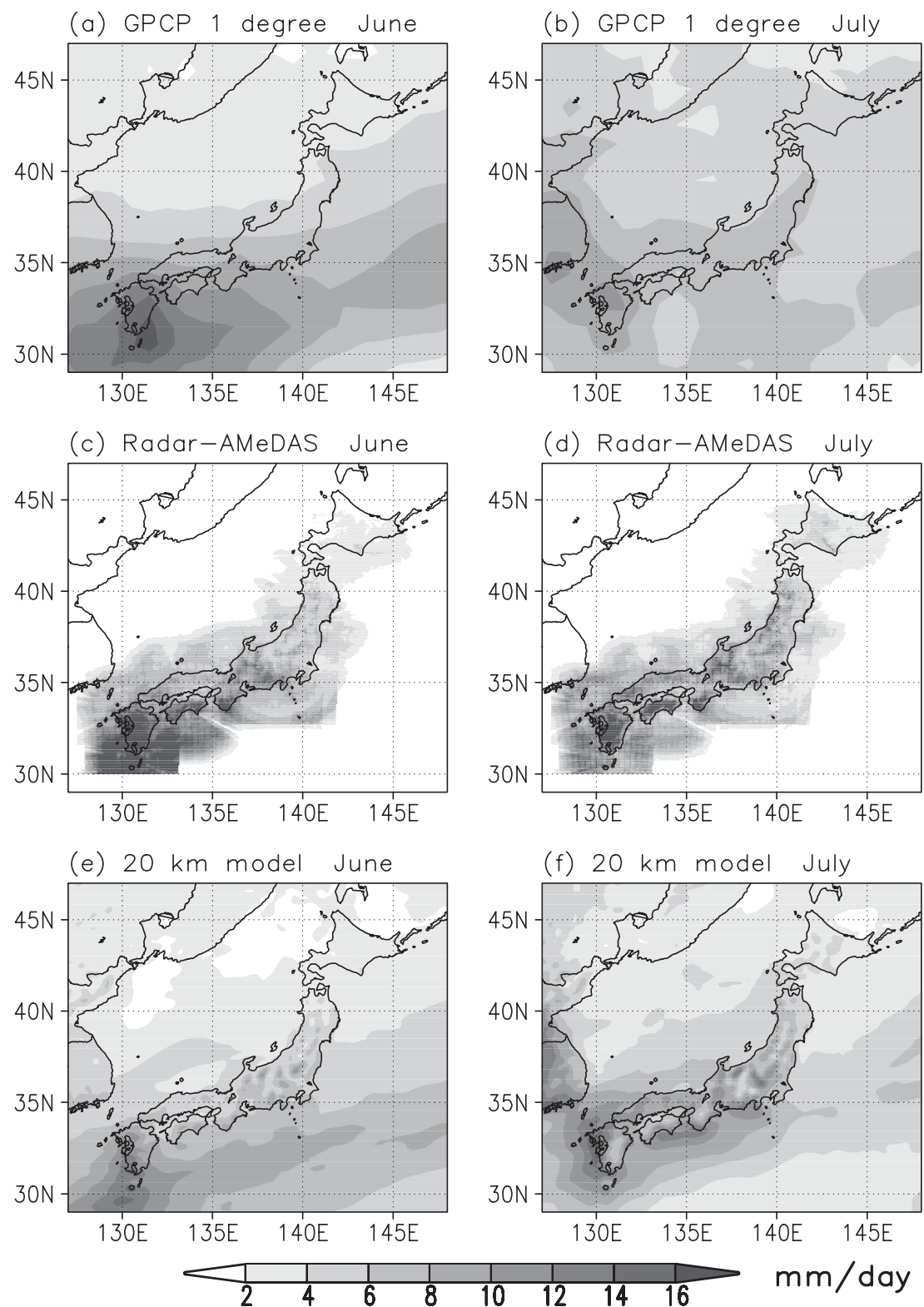

Fig. 6. Comparison of the simulated precipitation by the $20-\mathrm{km}$ model with observations of relatively higher horizontal resolution. The unit is $\mathrm{mm} \mathrm{day}^{-1}$. (a) GPCP one-degree daily precipitation dataset (Huffman et al. 2001) for June. Seven-year mean from 1997 to 2003. The grid spacing is about $90 \mathrm{~km}$ at $35^{\circ} \mathrm{N}$. (b) Same as (a), but for July. (c) Radar-mm day ${ }^{-1}$ ars calibrated using densely distributed (about 17-km mesh) rain gauges. Ten-year mean from 1991 to 2000. The horizontal resolution is about $5 \mathrm{~km}$. (d) Same as (c), but for July. (e) Simulated precipitation by the 20-km model for June. (f) Same as (e), but for July.

used for two datasets, and to the spatially dense data (about a $17-\mathrm{km}$ spacing) obtained from the Radar-AMeDAS data. In addition, the GPCP 2.5-degree precipitation in Fig. 3a appears to be underestimated compared with that in the Radar-AMeDAS data (Fig. 6d).

The observed and simulated precipitation intensities in June and July are depicted in Fig. 7. The precipitation simple daily intensity index (Frich et al. 1996) is defined as the total 

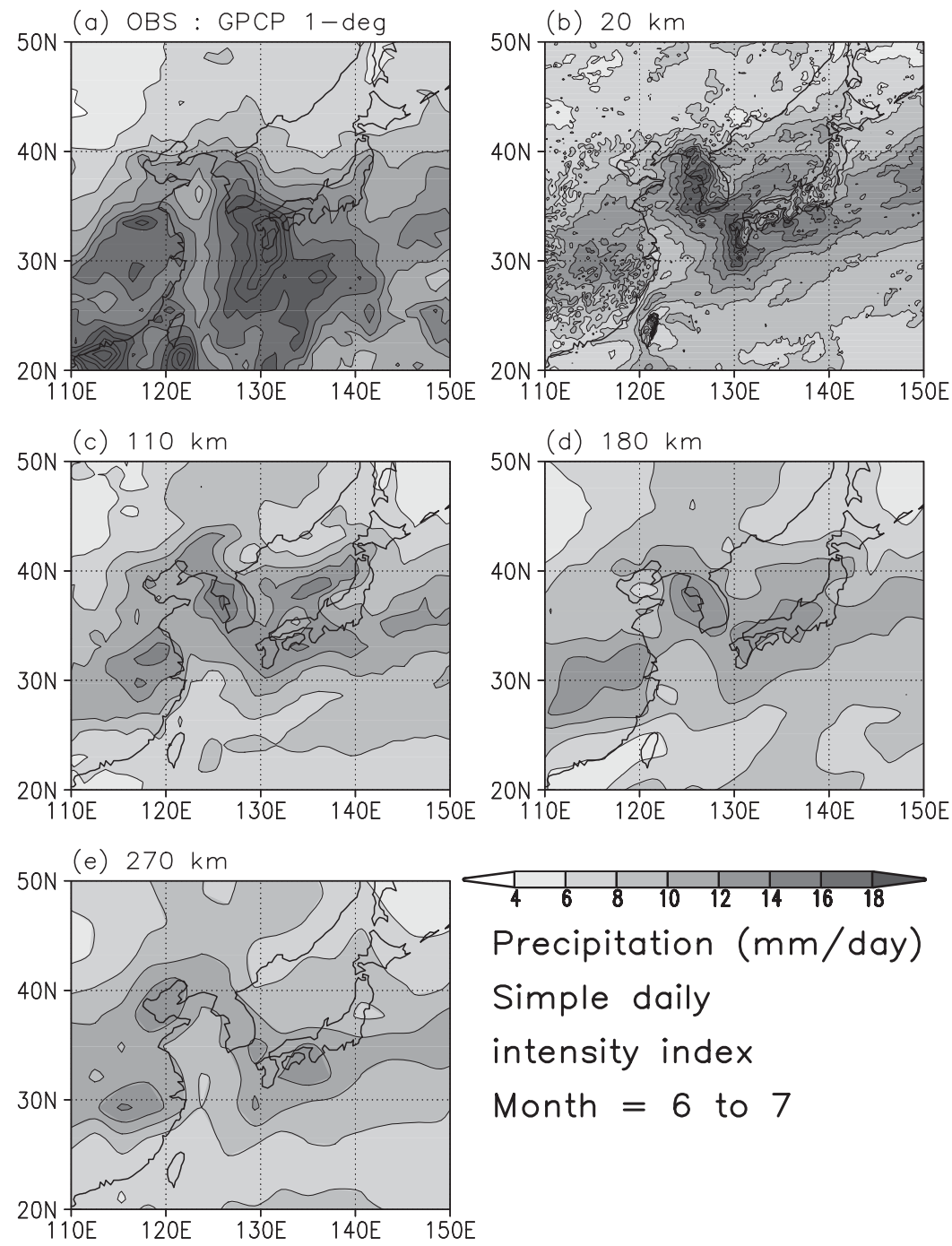

Simple daily

intensity index

Month $=6$ to 7

Fig. 7. Observed and simulated precipitation simple daily intensity index defined as the total precipitation divided by the number of rainy days (precipitation $\geq 1 \mathrm{~mm} \mathrm{day}{ }^{-1}$ ). The target period is from June to July. The contour interval is $2 \mathrm{~mm} \mathrm{day}^{-1}$. (a) GPCP one-degree daily precipitation dataset (Huffman et al. 2001) from 1997 to 2003. (b) Model climatology of 20-km horizontal resolution (TL959). The contour labels are omitted for legibility. (c) $110 \mathrm{~km}$ (TL159). (d) $180 \mathrm{~km}$ (TL095). (e) $270 \mathrm{~km}$ (TL063). The integration time is 10 years for all models with the same observed climatological SST.

precipitation in June and July divided by the number of rainy days (precipitation $\geq 1 \mathrm{~mm}$ day $^{-1}$ ). The $20-\mathrm{km}$ model (b) reproduces intense precipitation over China, Korea and Japan, although the intensity is still underestimated. With lower horizontal resolution models (c-e), it is more difficult to reproduce intense precipitation. The same analysis was also conducted for the number of heavy rain days (precipitation $\geq 30 \mathrm{~mm}$ day $^{-1}$ ) in June and
July. Similarly, the reproducibility of heavy rain days by the $20-\mathrm{km}$ model is higher than those of coarser models (Figure not shown).

In Fig. 8, the observed seasonal marching of precipitation is compared with the model simulations for the longitudinal sector including Japan. The target region is indicated by the boxes in Figs. $2 \mathrm{~b}$ and $3 \mathrm{~b}$. Hokkaido island in northern Japan $\left(140-145^{\circ} \mathrm{E}, 41-45^{\circ} \mathrm{N}\right)$ was excluded, because there is no Baiu season there. In mid- 
Precipitation ( $\mathrm{mm} /$ day) Pentad $=27$ to 46 Lon $=125$ to $142 \mathrm{E}$ Period=11 May to $18 \mathrm{Aug}$

(a) OBS : GPCP 2.5 degree 12 years(1982-1993)

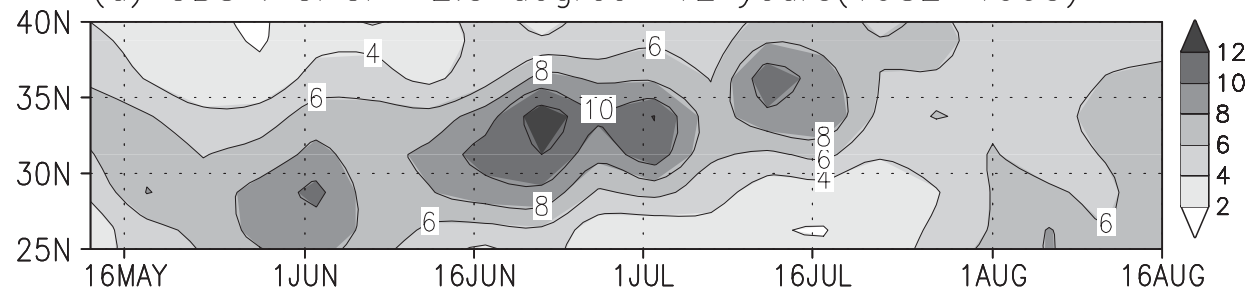

(b) $20 \mathrm{~km}$

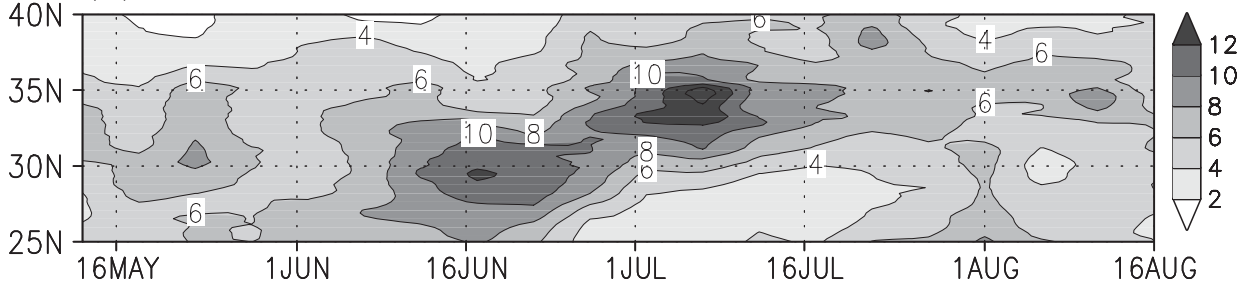

(c) $110 \mathrm{~km}$

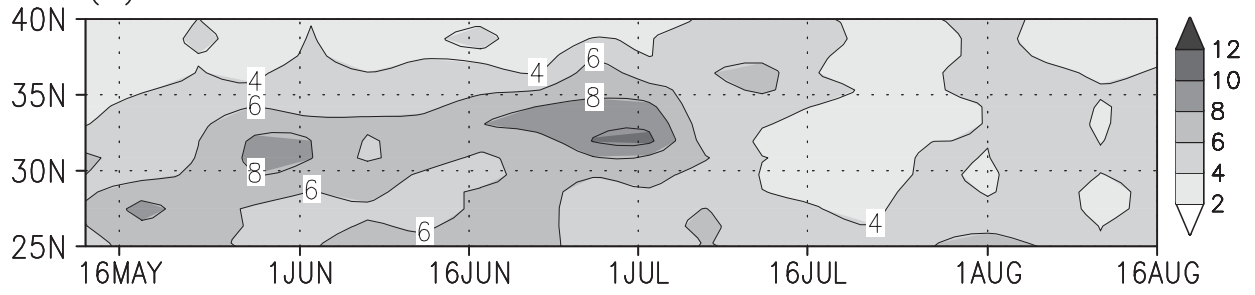

(d) $180 \mathrm{~km}$

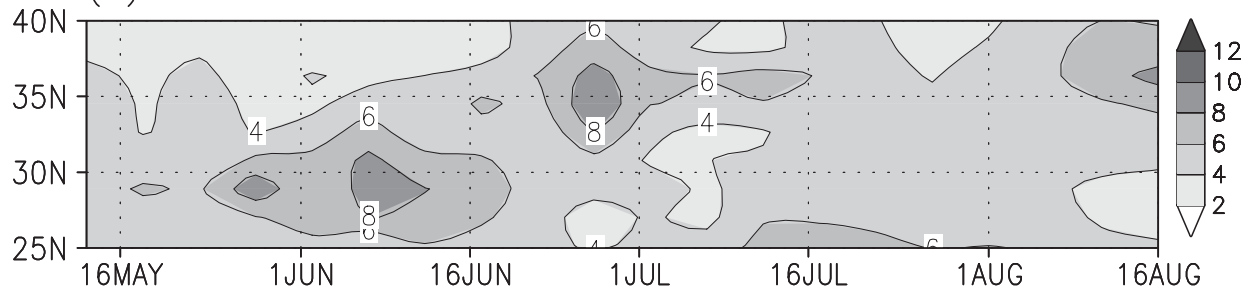

(e) $270 \mathrm{~km}$

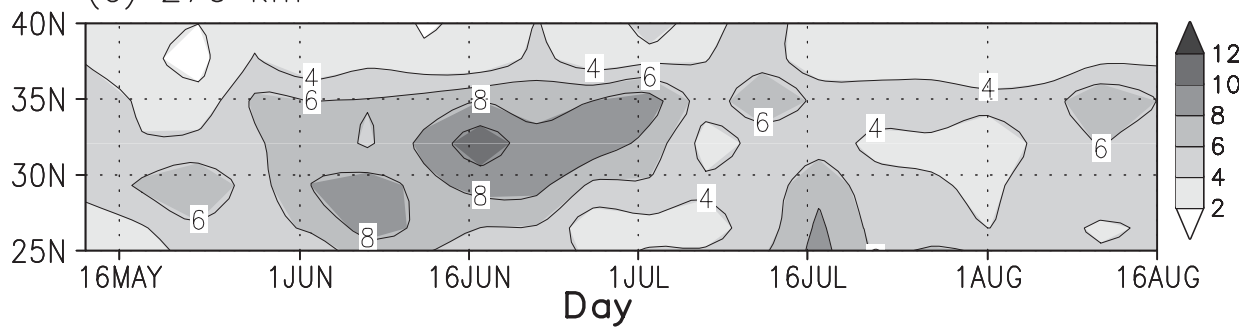

Fig. 8. Time-latitude cross section of the observed and simulated climatological pentad mean precipitation averaged for $125-142^{\circ} \mathrm{E}$. The target region is indicated in Figs. $2 \mathrm{~b}$ and $3 \mathrm{~b}$. The period is from pentad 27 (11-15 May) to 46 (14-18 Aug.). The contour interval is $2 \mathrm{~mm} / \mathrm{day}$. (a) Observation based on GPCP 2.5-degree data (Adler et al. 2003) from 1982 to 1993. (b) Model climatology of 20-km horizontal resolution (TL959). (c) $110 \mathrm{~km}$ (TL159). (d) $180 \mathrm{~km}$ (TL095). (e) $270 \mathrm{~km}$ (TL063). 
Precipitation Climatology

Pentad $=27$ to 46

Period $=11$ May to 18 Aug

Lon $=125-142 \mathrm{E} \quad$ Lat $=25-40 \mathrm{~N}$

(a) RMSE and Bias

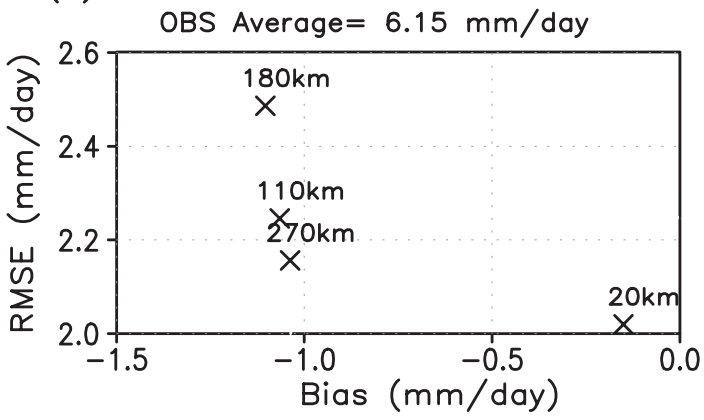

(b) Taylor diagram

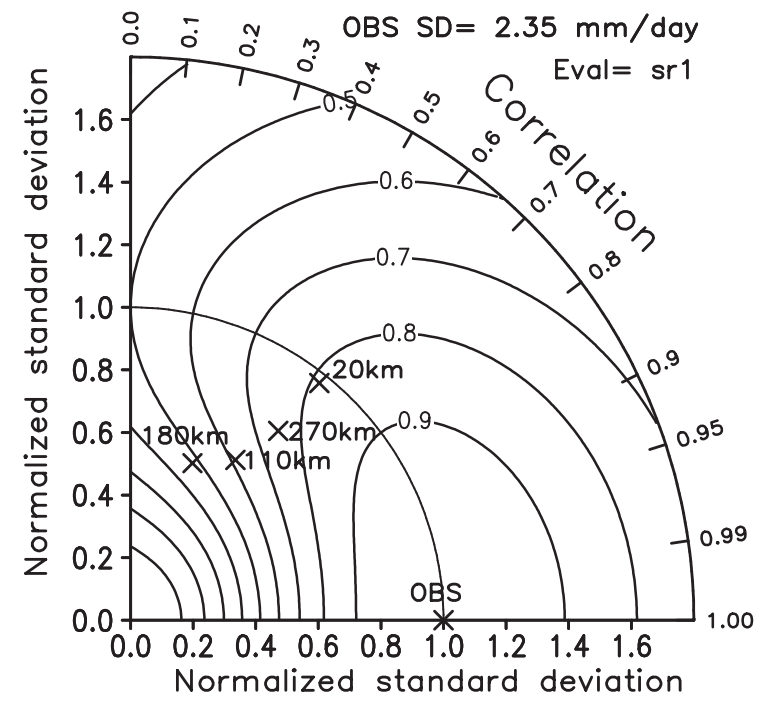

Fig. 9. Same as Fig. 4, but for the seasonal march of precipitation shown in Fig. 8.

May, an area of large precipitation was observed around $30^{\circ} \mathrm{N}$; it stagnated there until the beginning of June (Fig. 8a). This area of heavy rainfall then gradually migrated northward until mid-July and then disappeared. This band of northward-migrating rain corresponds to the Japanese rainy season, the Baiu. Coarser models (c-e) generally underestimate the amount of rainfall in the Baiu rain band, and do not show the northward migration. In contrast, the $20-\mathrm{km}$ model (b) accurately captures the northward migration of the Baiu rain band. However, the $20-\mathrm{km}$ model underestimates the amount of rainfall from the end of

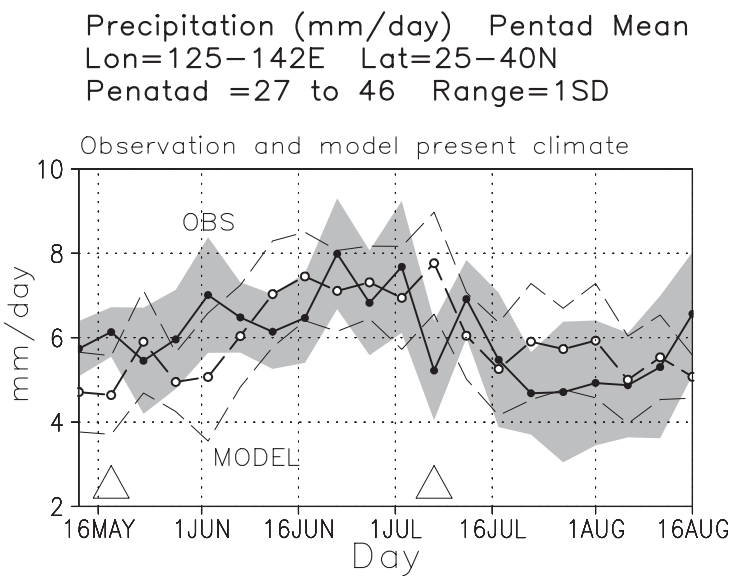

Fig. 10. Pentad mean time-series of observed and simulated climatological precipitation averaged for $\left(125-142^{\circ} \mathrm{E}\right.$, $\left.25-40^{\circ} \mathrm{N}\right)$. The target region is indicated in Figs. $2 \mathrm{~b}$ and $3 \mathrm{~b}$. The period is from pentad 27 (11-15 May) to 46 (1418 Aug.). Observation based on GPCP 2.5-degree data (Adler et al. 2003) is shown by thick solid line with closed circles. Shading shows the range of one standard deviation for the observed 12year period from 1982 to 1993 . The simulation by the $20-\mathrm{km}$ model is shown by the thick dash line with open circles. The thin dash lines show the range of one standard deviation for the simulated 10-year period. The unit is $\mathrm{mm} /$ day. The triangle mark in the bottom means that the difference between the observation and the present-day simulations is significant at the $90 \%$ level.

May to the beginning of June. The RMS difference, bias, and Taylor diagram were also calculated for the time-latitude field shown in Fig. 8. The $20-\mathrm{km}$ model shows the smallest RMS difference and bias compared with coarser models (Fig. 9a). In terms of the Taylor diagram (b), the $20-\mathrm{km}$ model is more accurate than coarser models, but the advantage is not as striking as that shown in panel (a).

Figure 10 illustrates the pentad mean precipitation time-series of observation and simulation by the $20-\mathrm{km}$ model averaged for the target region indicated in Figs. $2 \mathrm{~b}$ and $3 \mathrm{~b}$. The $20-\mathrm{km}$ model produces a reasonably accurate simulation of the observed seasonal variation in the amount of rainfall. 

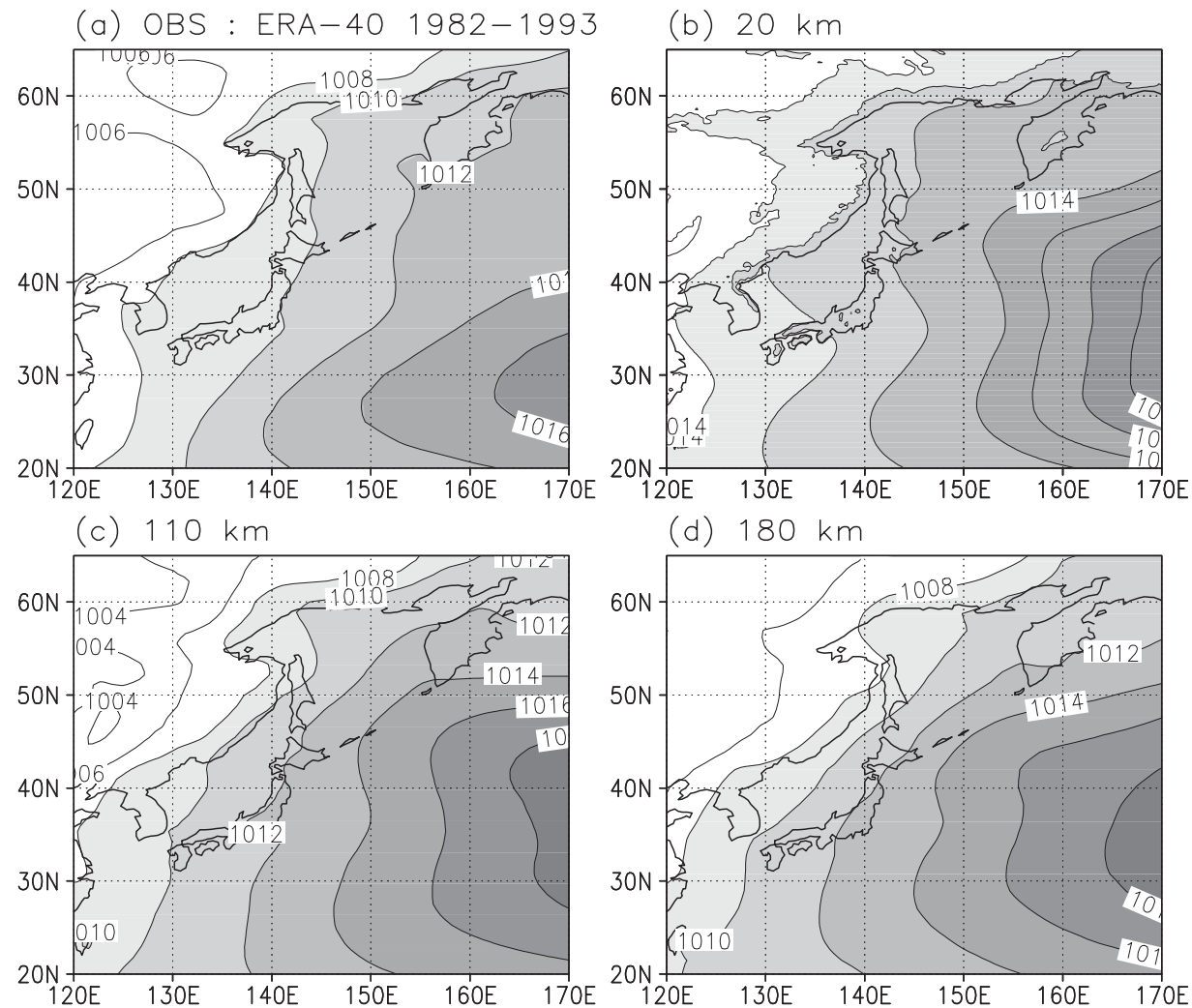

(d) $180 \mathrm{~km}$

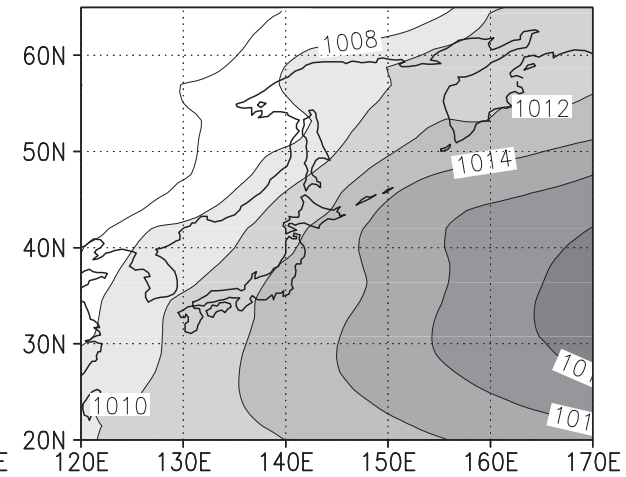

(e) $270 \mathrm{~km}$

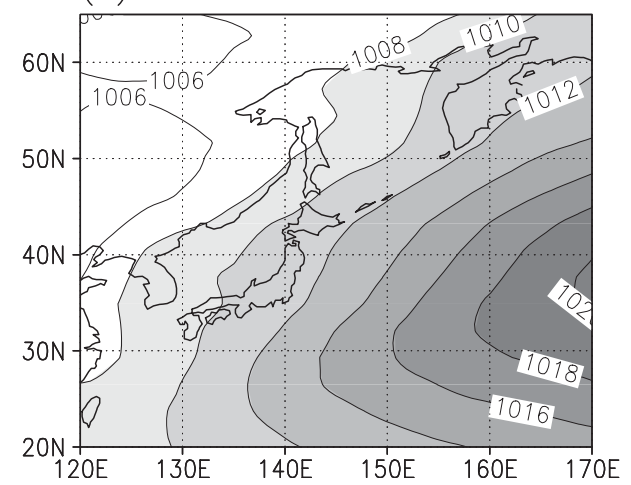

Mean sea level pressure

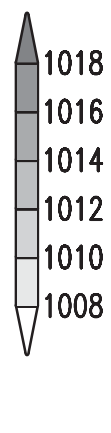

\section{$\mathrm{hPa}$ \\ Month $=6$}

Fig. 11. Observed and simulated climatological mean sea level pressure of June. The contour interval is $2 \mathrm{hPa}$. (a) Observation based on ERA-40 data (Simmons and Gibson 2000) averaged for 12 years, from 1982 to 1993 . The average period is identical to that of the observed climatological sea surface temperature (SST)s given to the models. The horizontal resolution is 2.5 degrees in longitude and latitude. (b) Model climatology of 20-km horizontal resolution (TL959). (c) $110 \mathrm{~km}$ (TL159). (d) $180 \mathrm{~km}$ (TL095). (e) $270 \mathrm{~km}$ (TL063). The integration time is 10 years for all models with the same observed climatological SST.

\subsection{Mean sea level pressure}

In Fig. 11, the reproducibility of the MSLP fields in June by the models is compared with the observations. All models accurately reproduce the Ogasawara high $\left(130-170^{\circ} \mathrm{E}, 20-\right.$ $\left.30^{\circ} \mathrm{N}\right)$. The strength of the simulated Okhotsk high, over the sea of Okhotsk $\left(140-155^{\circ} \mathrm{E}, 45-\right.$ $60^{\circ} \mathrm{N}$ ), increases as the horizontal resolution of the model increases. The Okhotsk high simulated by the $20-\mathrm{km}$ model has realistic horizon- 

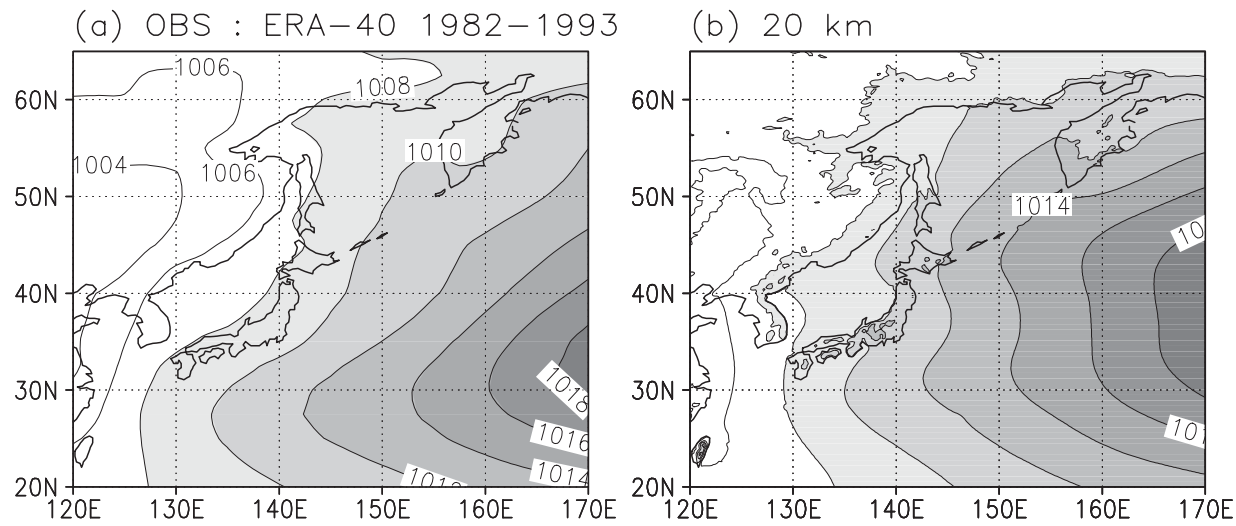

(c) $110 \mathrm{~km}$

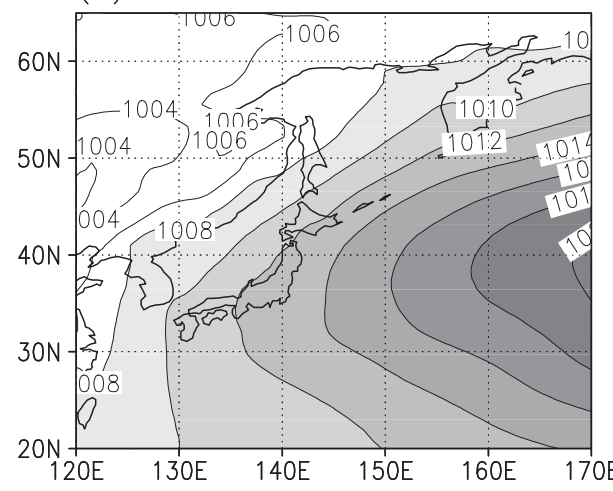

(d) $180 \mathrm{~km}$
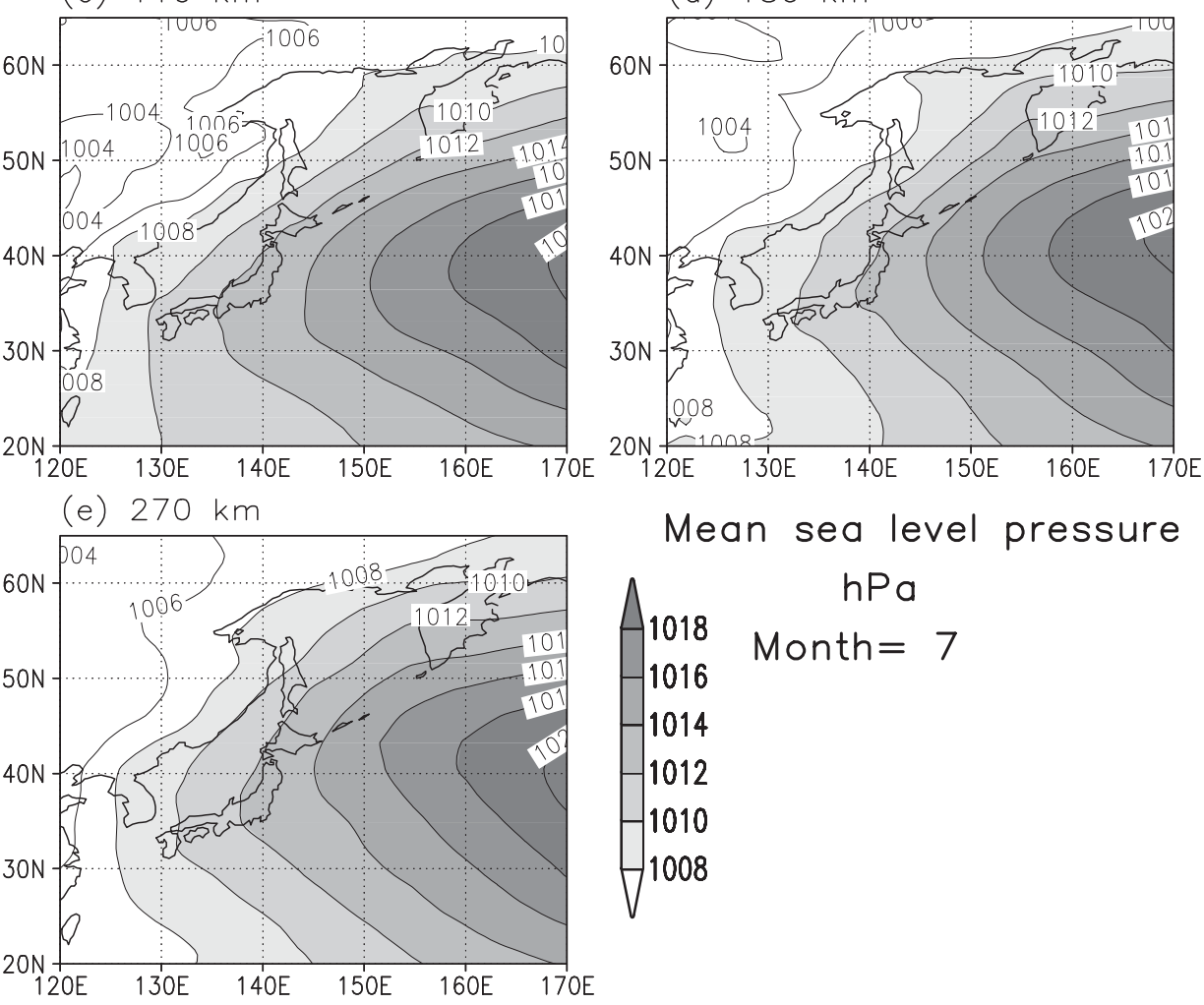

Mean sea level pressure

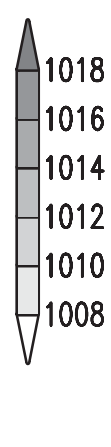

$\mathrm{hPa}$

\section{Month $=7$}

Fig. 12. Same as Fig. 11, but for July.

tal structure, but the strength is overestimated Between the Ogasawara high and the Okhotsk high, all models reproduce a relative lowpressure region over Japan around $35^{\circ} \mathrm{N}$, which corresponds to the Baiu rain band. The magnitude of the pressure drop over Japan is more enhanced as the horizontal resolution of the model increases. For July, shown by Fig. 12, the $20-\mathrm{km}$ model accurately reproduced a relative-low pressure region over Japan and the
Okhotsk high, while the coarser model did not.

Taylor diagrams are also calculated for MSLP. In June, the $20-\mathrm{km}$ model shows the smallest RMS, but the bias is comparable to that in coarser models (Fig. 13a). With regard to the Taylor diagram (b), the advantage of the $20-\mathrm{km}$ model is evident. For July, the $20-\mathrm{km}$ model shows the best performance with respect to the RMS and bias (Fig. 14a). With regard to the Taylor diagram (b), the $20-\mathrm{km}$ model shows 


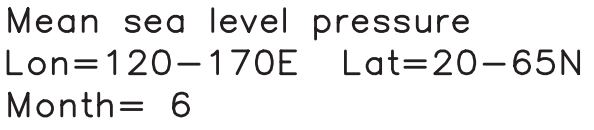

(a) RMSE and Bias

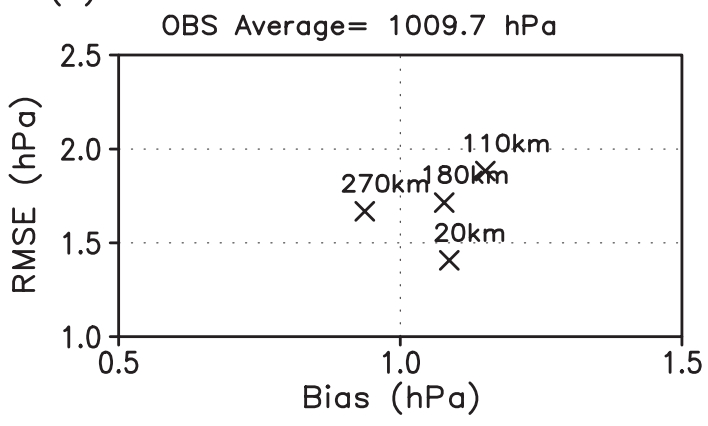

(b) Taylor diagram

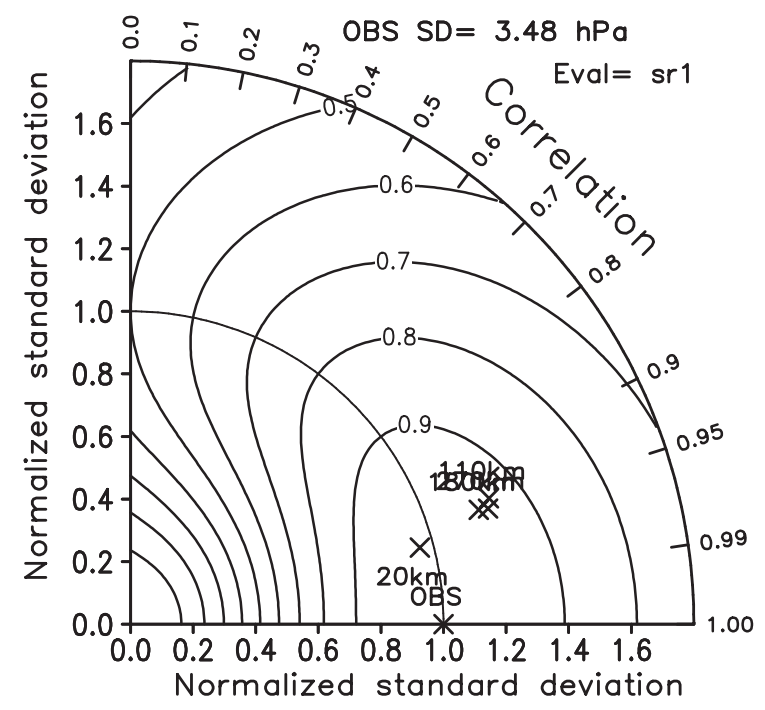

Fig. 13. Skill dependence of the geographical distribution of the mean sea level pressure on horizontal resolution $(\mathrm{km})$ of models for June. The verification data are ERA-40 data (Fig. 11a) and the target domain is the same as in Fig. $11\left(120-170^{\circ} \mathrm{E}, 20-65^{\circ} \mathrm{N}\right)$. (a) Root mean square error (RMSE)s and biases. The unit is hPa. (b) Taylor diagram for displaying pattern statistics (Taylor 2001). The figure format is the same as in Fig. 4.

the best performance as well, but the difference in accuracy is small among models. Similar verifications were conducted over the Ogasawara high $\left(130-170^{\circ} \mathrm{E}, 20-30^{\circ} \mathrm{N}\right)$ and the Okhotsk high $\left(140-155^{\circ} \mathrm{E}, 45-60^{\circ} \mathrm{N}\right)$ for June and July.

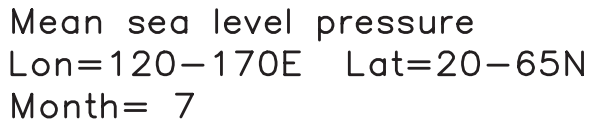

(a) RMSE and Bias

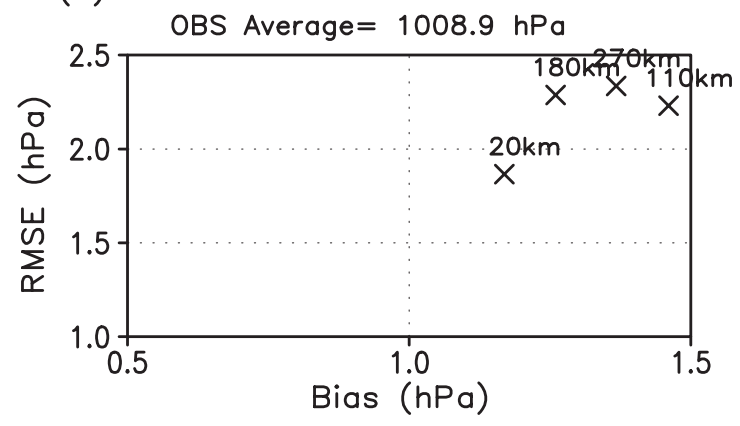

(b) Taylor diagram

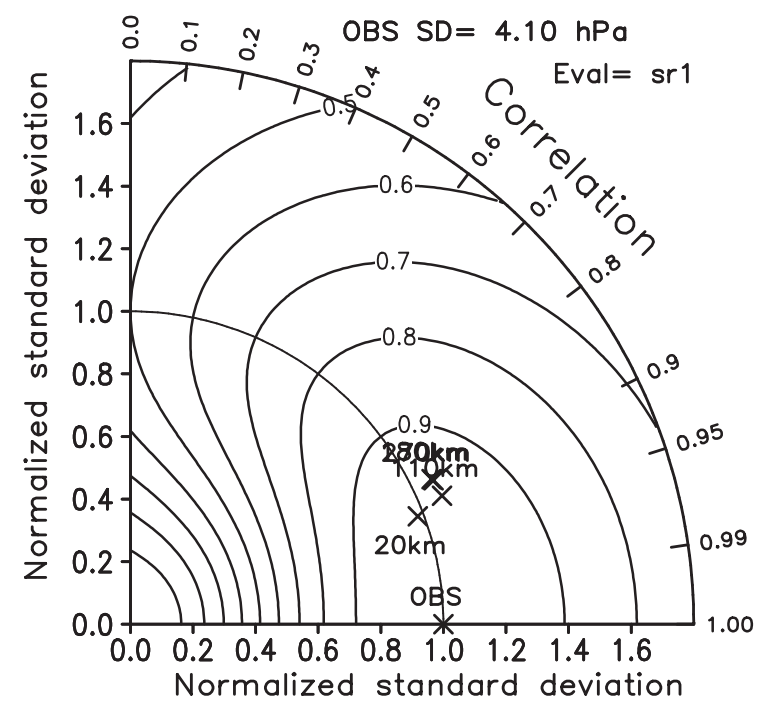

Fig. 14. Same as Fig. 13, but for July.

As for the Ogasawara high the skill difference among models is small both for June and July (figure not shown). In contrast, the advantage of the $20-\mathrm{km}$ model is striking in the Taylor diagram for both June and July (figure not shown), as is qualitatively indicated by Figs. 11 and 12 .

The verification of the $20-\mathrm{km}$ model, with respect to the geographical distribution of precipitation and its intensity, the seasonal march of the Baiu rain band, and the geographical distribution of MSLP, confirm that the $20-\mathrm{km}$ model generally exhibits a relatively higher performance than coarser models. This gives reliability, and credibility, to the future projection of the Baiu rain band in this study. 


\section{Future climate simulations}

\subsection{Precipitation}

Figure 15 illustrates the changes in precipitation for June simulated by models due to global warming. The projection by the $20-\mathrm{km}$ model shows that precipitation increases over the Yangtze River valley of China, the East China Sea, western Japan, and over the ocean to the south of the Japan archipelago. On the contrary, the precipitation decreases over some regions of northern Japan (a). An increase in precipitation over the East China Sea is also projected by the $110-\mathrm{km}$ (b), $180-\mathrm{km}$ (c), and CGCM2.3 (e) models, but the 270-km (d) model exhibits a decrease in precipitation. The SSTs and experimental design in the CGCM2.3 simulation, are different from those of other simulations $(\mathrm{a}-\mathrm{d})$; therefore, a direct comparison may not be appropriate.

The July case is shown in Fig. 16 . The $20-\mathrm{km}$ model (a) projects a precipitation increase over the Yangtze River valley of China, the East China Sea, western Japan, and over the ocean to the south of the Japan archipelago. On the contrary, precipitation decreases over the Korean peninsula and northern Japan. Although statistically significant regions are restricted to some part of the East China Sea and northern Japan, the area of significant regions is larger than that of those in the June case (Fig. 15a). An increase of precipitation over the East China Sea is also projected by other coarser models (Figs. 16b-e).

The study by Kitoh et al. (2005; A2, B2 scenario) with a former version of MRI-CGCM2 indicated a summertime precipitation increase over the Yangtze River valley of China. Using state-of-the-art high-resolution AOGCM, with the A1B scenario, Kimoto (2005) and Kimoto et al. (2005) projected an increase in the summertime precipitation increase over the East China Sea, Korea, and all of Japan. The changing tendencies of precipitation over Korea and northern Japan are opposite to those obtained in the present study. Regional climate models have also been used to project change in the local climate over Japan. Kurihara et al. (2005; A2 scenario) found increases in the summertime precipitation in western Japan with the $20-\mathrm{km}$ mesh regional model, nested into a former version of MRI-CGCM2.
The change in the intensity of precipitation in June and July is illustrated in Fig. 17. Both the simple daily intensity index (Frich et al. 2002), and the number of heavy rain days (precipitation $\geq 30 \mathrm{~mm}$ day $^{-1}$ ), increased over the Yangtze River valley of China and the East China Sea. In contrast, the intensity decreased over Korea. The regions of increased and decreased intensity approximately coincide with the regions of increased and decreased total precipitation (Figs. 15a and 16a), respectively.

Kitoh et al. (2005) also pointed out that the intensity of summertime precipitation increased over the Yangtze River valley of China. Kimoto et al. (2005) reported that the intensity of summertime precipitation increased over the East China Sea, Korea, and all of Japan. Yoshizaki et al. (2005) and Yasunaga et al. (2005) have conducted global warming projections using a cloud-resolving, non-hydrostatic $5-\mathrm{km}$ mesh regional model nested into the $20-\mathrm{km}$ model used in this paper. They found the frequency of occurrence of heavy rainfall increases over the Japan Islands.

The change in the seasonal march of the Baiu rain band, simulated by the $20-\mathrm{km}$ model, is depicted in Fig. 18. In mid June, the position of the Baiu rain band in the future-climate simulations (Fig. 18b) shifts more to the north than the present-day position does (Fig. 18a). The northward migration of the Baiu rain band in the future climate is not as evident as in the present-day climate, and the Baiu rain band tends to stagnate around $30-35^{\circ} \mathrm{N}$ until the beginning of August. This means that the termination of the Baiu period is delayed until August, while the Baiu season in the present-day climate terminates in the middle of July. The change in precipitation due to global warming is depicted in Fig. 18c. A significantly large precipitation increase is found especially in July around $30^{\circ} \mathrm{N}$. An increase in precipitation is also evident in August around $30-35^{\circ} \mathrm{N}$, suggesting a delay in the termination of the Baiu season. However, this precipitation increase in August is not statistically significant.

Figure 19 illustrates the pentad mean precipitation time-series of present-day and future simulation by the $20-\mathrm{km}$ model over Japan. The averaged region is indicated by the boxes in Figs. $2 \mathrm{~b}$ and $3 \mathrm{~b}$. The onset date of the Baiu season is around the beginning of June in the 

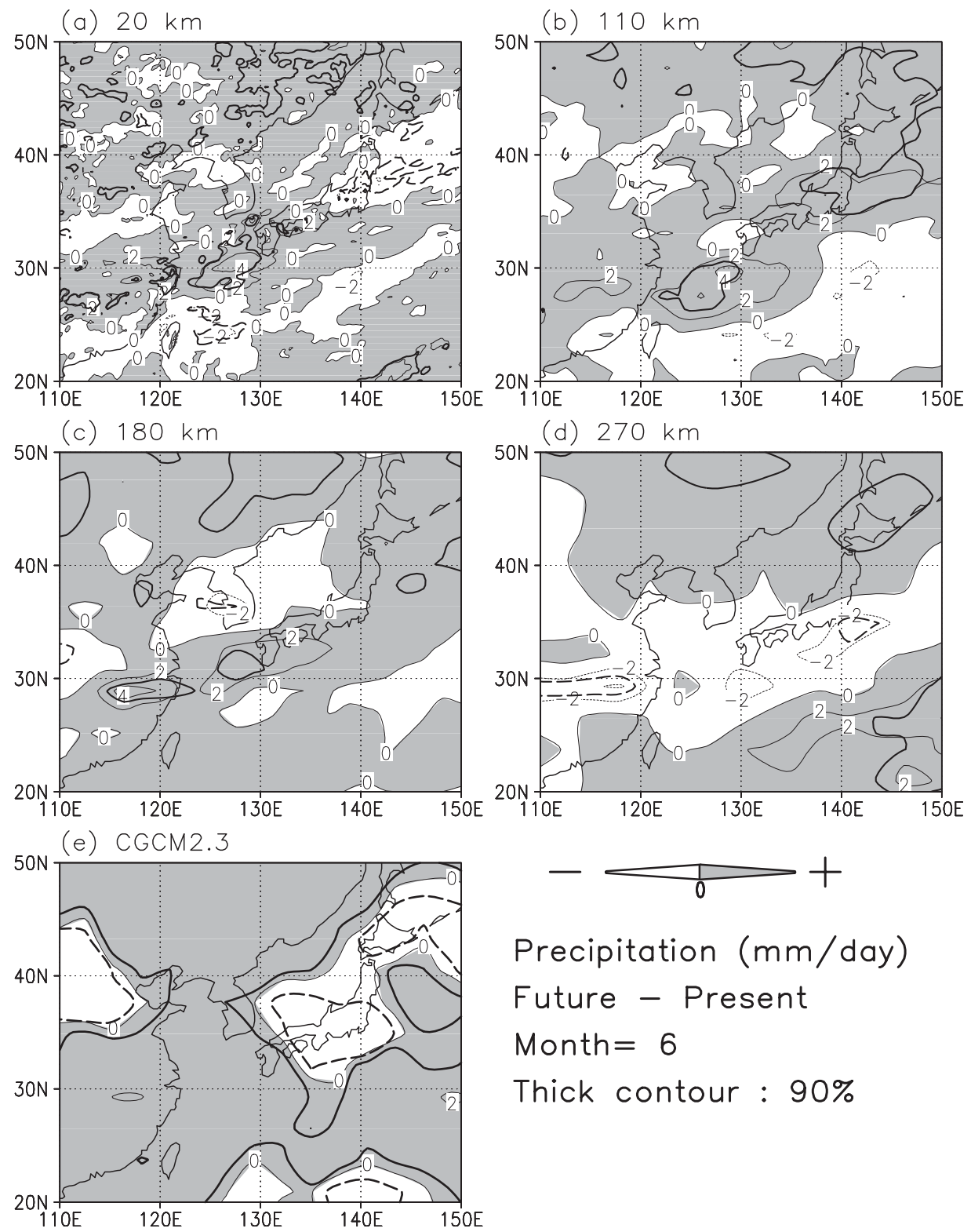

Precipitation ( $\mathrm{mm} / \mathrm{day}$ )

Future - Present

Month $=6$

Thick contour : $90 \%$

Fig. 15. Change of precipitation as future minus present-day simulations for June. The positive values are shaded. The contour interval is $2 \mathrm{~mm} \mathrm{day}^{-1}$. Thick solid and thick dashed contours show a $90 \%$ significance level. (a) Change simulated by the model of $20-\mathrm{km}$ horizontal resolution (TL959). (b) $110 \mathrm{~km}$ (TL159). (c) $180 \mathrm{~km}$ (TL095). (d) $270 \mathrm{~km}$ (TL063). (e) Change simulated by the coupled model CGCM2.3 as future simulations (A1B scenario, 2081-2090) minus presentday simulations (20th Century simulation, 1981-1990). The ensemble size is five for present and future simulations, respectively. The horizontal resolution of the atmospheric part is about $270 \mathrm{~km}$. SST distributions are not identical to those for (a) to (d). Significant regions are larger than those of (a) to (d) mainly due to the five-times-larger sample size.

present-day simulation, but the onset date will not be greatly changed in the future simulation. In the mature stage of the Baiu season from mid-June to the beginning of July, precip- itation in the future simulation increases, compared with the present-day simulation. Nevertheless, the large standard deviations both for the present-day and future simulations prevent 

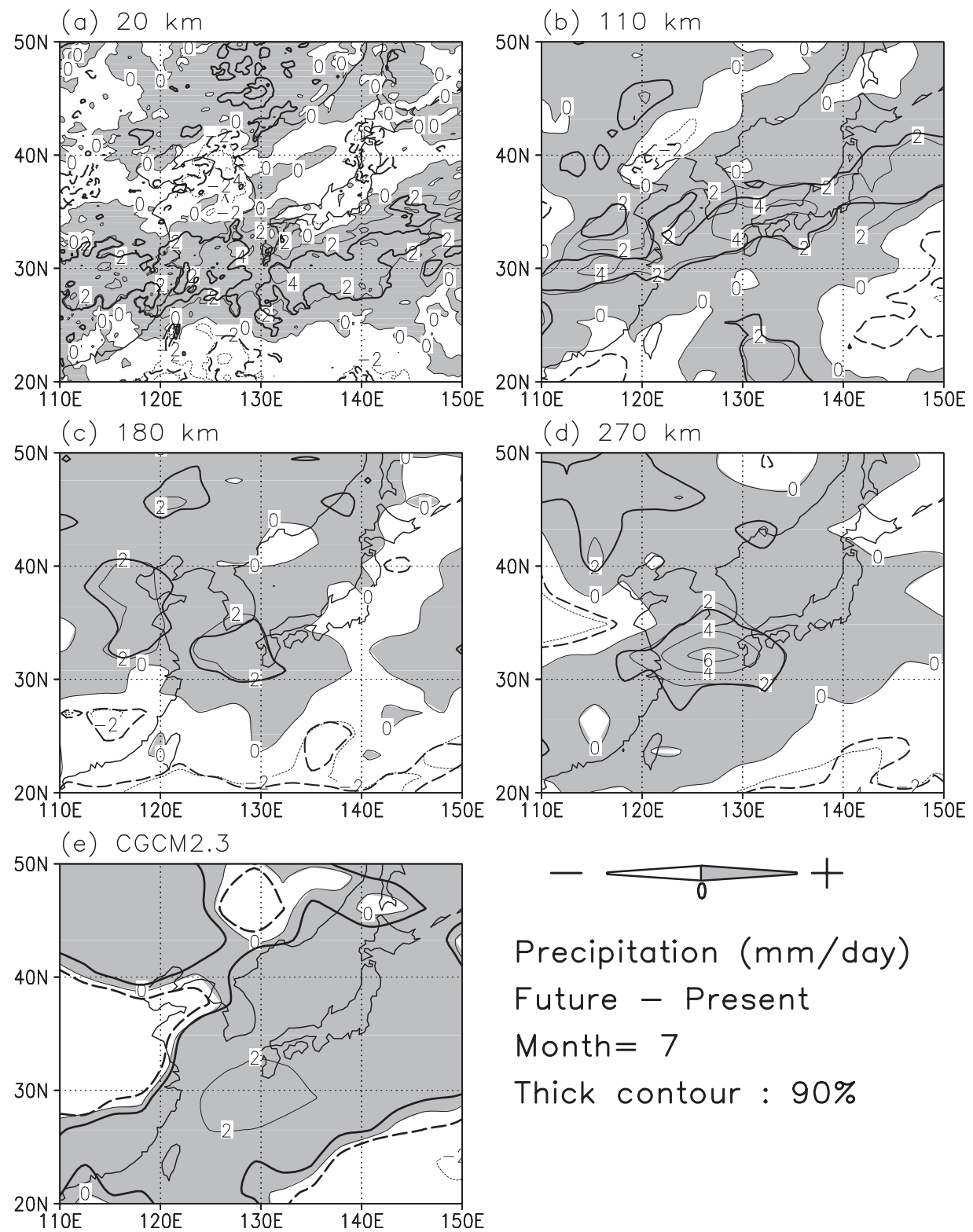

Precipitation ( $\mathrm{mm} / \mathrm{day}$ )

Future - Present

Month $=7$

Thick contour : $90 \%$

Fig. 16. Same as Fig. 15, but for July.

us from concluding that this change is statistically significant. Figure 19 suggests that the termination of the Baiu season in the presentday simulation is around mid-June. From midJuly to mid-August, precipitation in the future simulation is larger than that in the presentday simulation, again suggesting a delay in the termination of the Baiu season. However, this change is only statistically significant for the pentad 41 (20-24 Jul.).
Kitoh and Uchiyama (2006) have analyzed a future change in the Baiu season for seven AOGCMs, including MRI-CGCM2.3 used in this present study. All seven projections use the same emission scenario of A1B. They revealed that the withdrawal dates of the Baiu season are delayed, while the changes in the onset dates are small. Our results are consistent with theirs. The study by Yasunaga et al. (2006), with a non-hydrostatic 5-km-mesh re- 

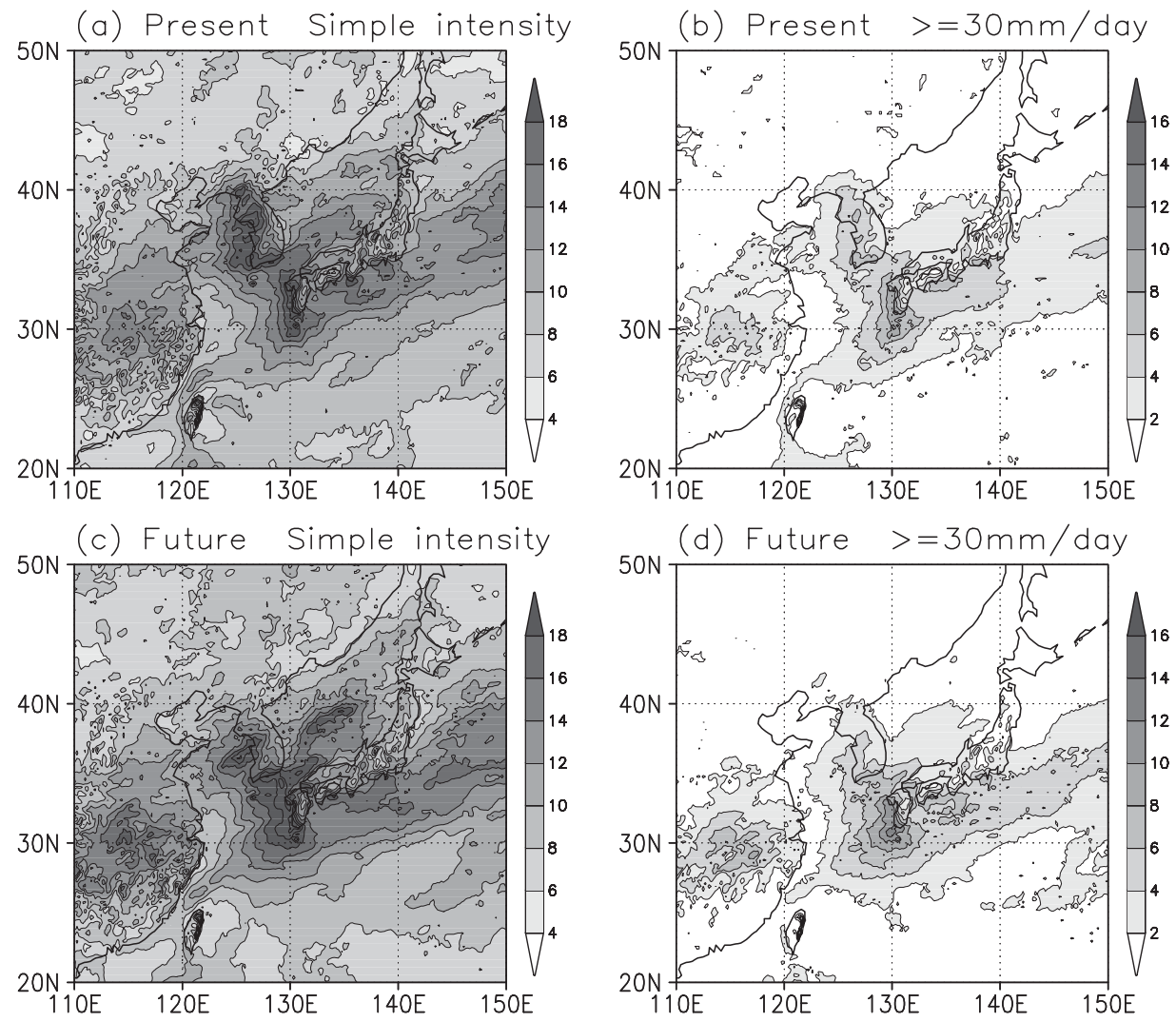

(e) Future/Present (\%)
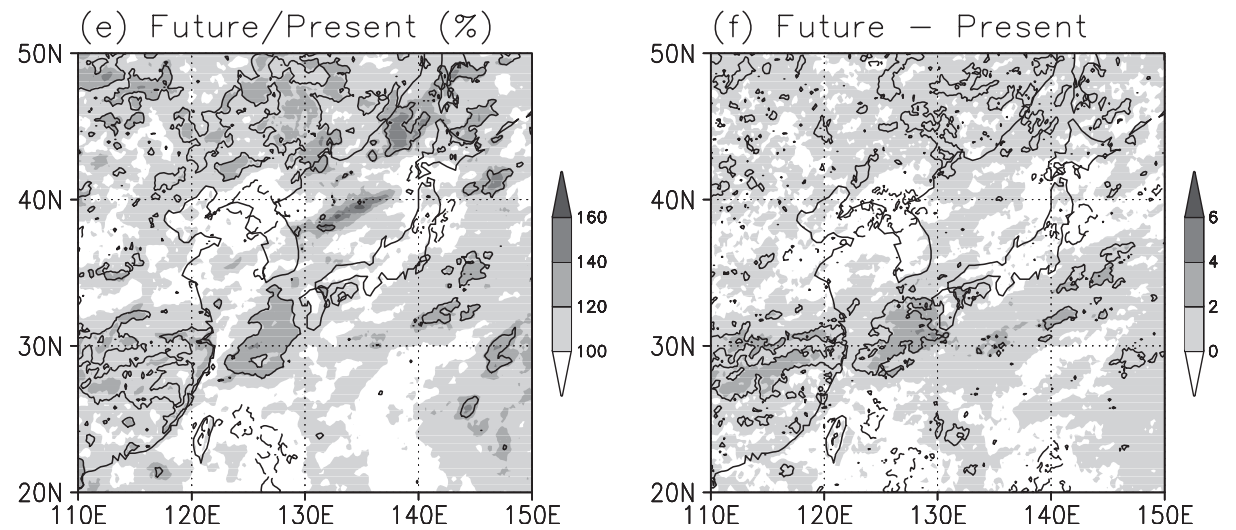

Fig. 17. Change of the daily precipitation intensity simulated by the $20-\mathrm{km}$ model for June to July. (a) Present-day climatology of the simple daily intensity index (Frich et al. 2002), which is defined as the total precipitation divided by the number of rainy days (precipitation $\geq 1 \mathrm{~mm} \mathrm{day}^{-1}$ ). The contour interval is $2 \mathrm{~mm}^{-1 a y}{ }^{-1}$. (b) Present-day climatology of the number of heavy rain days (precipitation $\geq 30 \mathrm{~mm} \mathrm{day}^{-1}$ ). The contour interval is 2 days. (c) Same as (a), but for future climatology. (d) Same as (b), but for future climatology. (e) Change of the intensity as the ratio of future climatology (e) to present-day climatology (a). The unit is \%. Values greater than $100 \%$ are shaded. Solid and dashed contours show a $90 \%$ significance level. (f) Change in the number of days with precipitation $\geq 30 \mathrm{~mm} /$ day as future minus present-day climatology. The unit is day. Positive values are shaded. Solid and dashed contours show a $90 \%$ significance level. 
Precipitation ( $\mathrm{mm} /$ day) Pentad $=27$ to 46

Lon $=125$ to $142 \mathrm{E}$ Period=11 May to 18 Aug

(a) Present

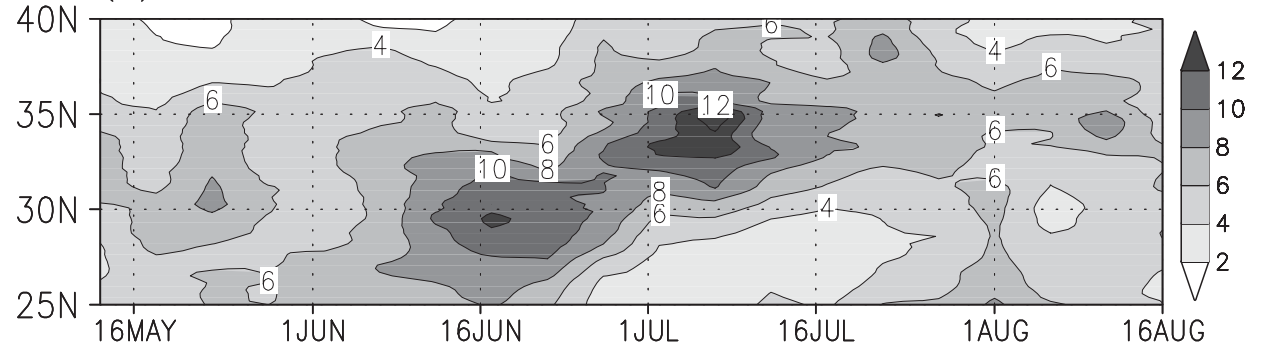

(b) Future

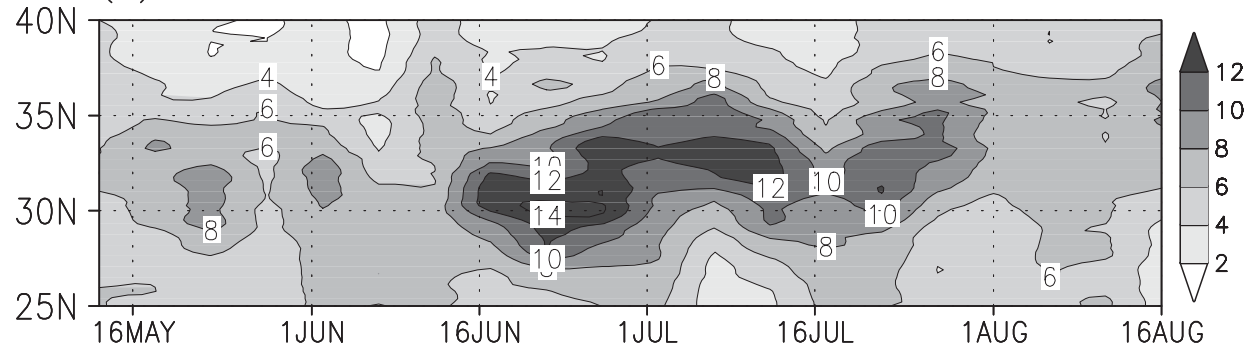

(c) Change $=$ Future - Present

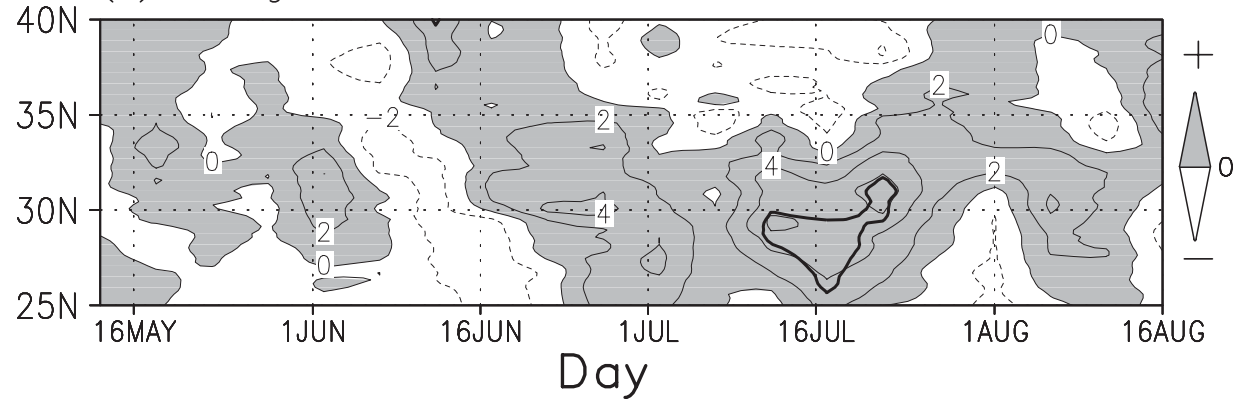

Fig. 18. Time-latitude cross section of the climatological pentad mean precipitation simulated by the $20-\mathrm{km}$ model averaged for $125-142^{\circ} \mathrm{E}$. The target region is indicated in Figs. $2 \mathrm{~b}$ and $3 \mathrm{~b}$. The period is from pentad 27 (11-15 May) to 46 (14-18 Aug.). The contour interval is $2 \mathrm{~mm} / \mathrm{day}$. (a) Presentday climatology. This panel is identical to Fig. 8b. (b) Future climatology. (c) Change as future minus present-day climatology. Positive values are shaded. The thick contour shows a $90 \%$ significance level.

gional model, has also indicated the delay in the withdrawal date of the Baiu season. Our result is consistent with the results above.

\subsection{Mean sea level pressure}

Figure 20 illustrates the change in the MSLP simulated by the $20-\mathrm{km}$ model for June and July. In June, the MSLP decreases over the entire displayed domain. The MSLP decrease over the East China Sea can be related to the enhancement of convection, resulting in the in- crease of precipitation there (Fig. 15a). However, the relationship between the relatively large decrease of the MSLP north of $40^{\circ} \mathrm{N}$, and the change in precipitation is not clear. In July, the MSLP over Japan decreases, indicating an intensification of the Baiu rain band. On the contrary, the MSLP to the south of Japan and over the Okhotsk high increases, indicating the intensification of both the Ogasawara and the Okhotsk high, although the intensification of the Okhotsk high is not statistically significant. 


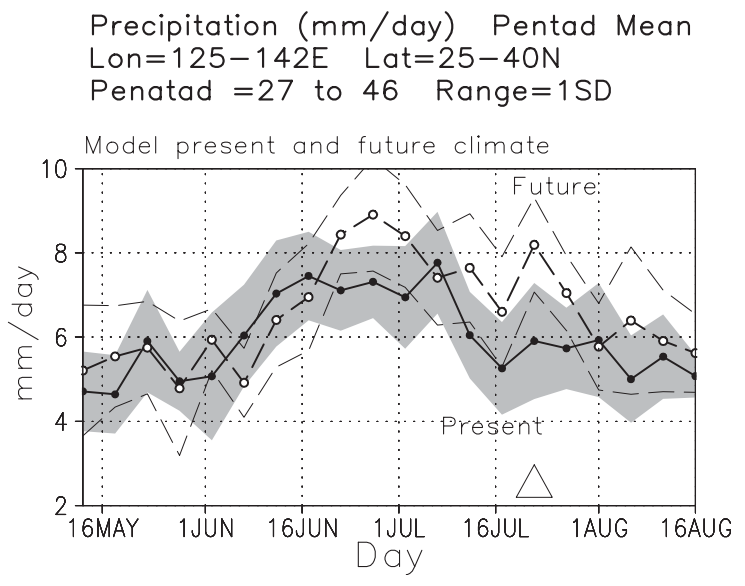

Fig. 19. Pentad mean time-series of climatological precipitation simulated by the $20-\mathrm{km}$ model averaged for (125$\left.142^{\circ} \mathrm{E}, 25-40^{\circ} \mathrm{N}\right)$. The target region is indicated in Figs. $2 \mathrm{~b}$ and $3 \mathrm{~b}$. The period is from pentad 27 (11-15 May) to 46 (14-18 Aug.). The thick solid line with closed circles shows the present-day climatology. Shading shows the range of one standard deviation. A thick dashed line with open circles shows future climatology. The thin dash lines show the range of one standard deviation. The triangle mark in the bottom means that the difference between the presentday and future simulations is significant at the $90 \%$ level.

This strengthening of two highs is consistent with the results by Kimoto (2005) using 18 AOGCM projections. The intensification of the Ogasawara high in July also indicates a tendency of the high to stagnate to the south of Japan, which leads to a delay in the termination of the Baiu season.

The summertime intensification of the Ogasawara high in a future warmer climate is also projected with AOGCM by Kitoh et al. (1997), and with regional models by Kato et al. (2001) and Kurihara et al. (2005). In the present-day climate of July, the relatively higher-SST region is located to the east of the Philippine Islands (Fig. 1b). On the other hand, in the future climate, the higher-SST region shifts to near the equator around $150-180^{\circ} \mathrm{E}$ (Fig. 1d). Yasunaga et al. (2006) attributed the intensification and stagnation of the Ogasawara high in the fu- ture climate, to the concentration of active convection over this equatorial higher SST region. This higher-SST region might lock the position of the Ogasawara high, and hinder the high from moving northward.

\subsection{Water vapor flux}

Figure 21 illustrates the present-day simulation (b), future simulation (c) and change (d) of the vertically integrated water vapor flux, and its convergence for July together with the observed climatology for verification (a). The 20$\mathrm{km}$ model (b) accurately simulates the observed clockwise transport of water vapor around the rim of the Ogasawara high to the south of Japan, which is recognized as an important factor to provide a large amount of precipitation within the Baiu rain band (Ninomiya and Akiyama 1992). In addition, the model accurately simulates the northeastward water vapor transport over the South China Sea. As a result, the model accurately reproduces the large convergence area of water vapor flux over Korea and Japan, corresponding to the Baiu rain band. Thus, the validity of the simulated water vapor flux distribution, as well as its convergence, leads to a realistic simulation of the Baiu rain band in the present-day climate.

The change of water vapor flux (d) suggests the intensification of clockwise transport over the Ogasawara high, resulting in an increase in the convergence over the Yangtze River valley, the East China Sea, Western Japan, and over the ocean to the south of the Japan archipelago. First, this water vapor flux change is caused by water vapor increases, mainly in the lower troposphere, associated with the temperature rise due to warming, as expected from the Clausius-Clapeyron relation. Secondly, this change in the water vapor flux is caused by the intensification of a clockwise low-level flow over the Ogasawara high. The relative magnitude of the contribution from these two factors will be qualitatively estimated in the next section. In contrast, the decrease in the convergence appears over the Korean peninsula and Northern Japan. This distribution of the divergence change (Fig. 21d) bears a close resemblance to that of the precipitation change (Fig. 15a), suggesting that the future precipitation change is mainly attributable to the change in the horizontal transport of the water vapor flux. 

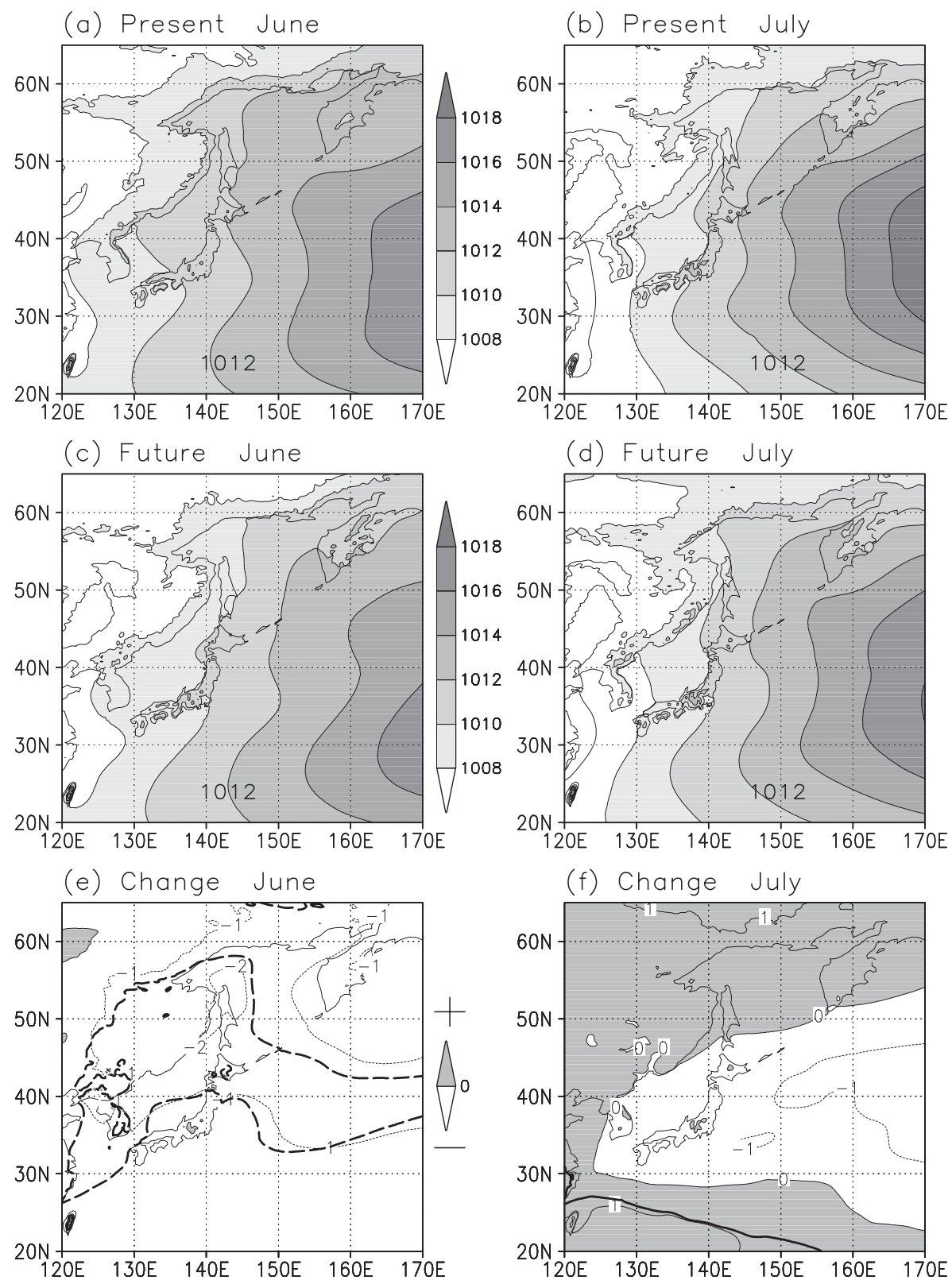

Fig. 20. Change of the mean seal level pressure simulated by the 20-km model. (a) Present-day climatology for June. This panel is identical to Fig. 11b. The contour interval is $2 \mathrm{hPa}$. (b) Presentday climatology for July. This panel is identical to Fig. 12b. Contour interval is $2 \mathrm{hPa}$. (c) Same as (a), but for future climatology. (d) Same as (b), but for future climatology. (e) Change as future minus present-day climatology. The contour interval is $1 \mathrm{hPa}$. Positive values are shaded. Thick solid and thick dashed contours show the $90 \%$ significance level. (f) Same as (e), but for July.

\section{Discussion}

In order to interpret the model response in a future warmer climate, the anomaly composite maps of precipitation (Fig. 22a) and water va- por flux and its convergence (Fig. 22b), were synthesized using eight El Niño years. Deviations are calculated from an average of twelve non-El Niño and Southern Oscillation (ENSO) years. The definition of El Niño follows the op- 

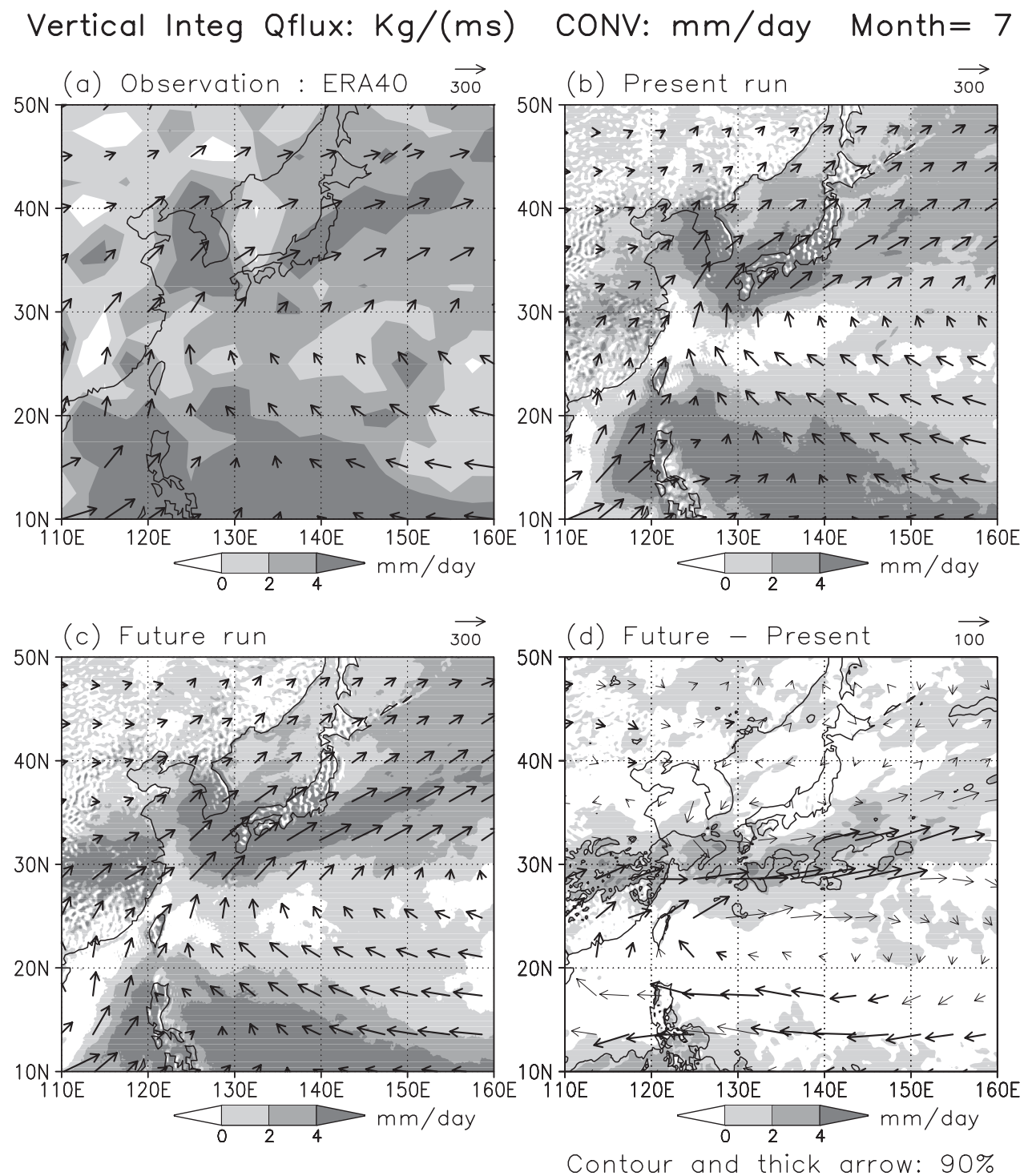

Fig. 21. Vertically integrated water vapor flux (arrow) and its convergence (shading) of July. The unit of water vapor flux is $\mathrm{Kg} \mathrm{m}^{-1} \mathrm{~s}^{-1}$ ). The unit of convergence is converted to $\mathrm{mm} /$ day assuming the density of liquid water as $1 \mathrm{~g} \mathrm{~cm}^{-3}$. Calculations are based on 6-hourly data of the water vapor and wind vector. (a) Observation based on ERA-40 data averaged for 12 years from 1982 to 1993. The contour interval is $2 \mathrm{~mm} \mathrm{day}^{-1}$. The top pressure level is $1 \mathrm{hPa}$. (b) Present-day climatology of the $20-\mathrm{km}$ model. The top pressure level is $0.4 \mathrm{hPa}$. The difference of the top level between the ERA-40 $(1 \mathrm{hPa})$ and the model $(0.4 \mathrm{hPa})$ is negligible in the vertical integration of the water vapor flux, because majority of the water vapor is confined to the lower troposphere. (c) Future climatology. (d) Change as present-day minus future climatology. The contour and thick arrow show a $90 \%$ significance level of the convergence and water vapor flux, respectively.

erational criterion of JMA. The observed precipitation anomaly for the El Niño years (a) is almost similar to the precipitation change in a future climate (c), albeit with some differences in higher latitudes. Moreover, the observed wa- ter vapor flux anomaly and its convergence for El Niño years (b) resemble the change in water vapor flux and its convergence in a future climate (d), albeit with some differences. The spatial structure of the SST change by the 

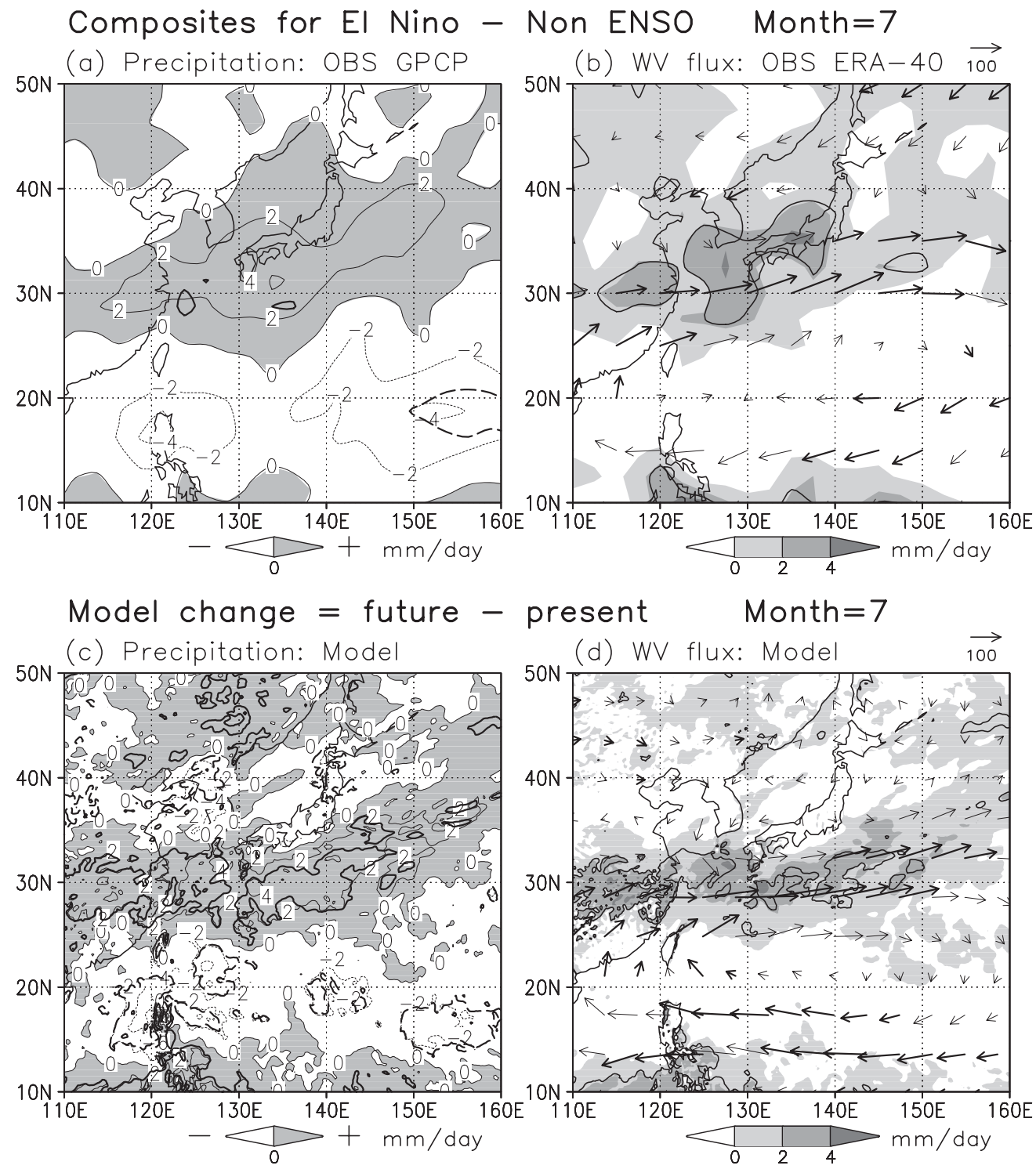

Fig. 22. (a) Difference of the precipitation distribution of eight El Niño years $(1982,83,87,91,92$, 93, 97, and 98) from twelve Non-El Niño and Southern Oscillation (ENSO) years (1979, 80, 81, 84, 86, 90, 91, 94, 95, 96, 2000, and 2001) for July. The definition of El Niño follows the operational criterion used by the Japan Meteorological Agency (JMA): El Niño occurs when the five-month running mean sea surface temperature (SST) is more than 0.5 degrees above normal for six months or more in the Niño 3 region $\left(4^{\circ} \mathrm{S}-4^{\circ} \mathrm{N}, 150-90^{\circ} \mathrm{W}\right)$. SSTs are based on the JMA operational analysis, and the SST climatology is the 30-year average from 1961 to 1990. Precipitation of GPCP 2.5degree data from 1979 to 2001 is used for a composite. The contour interval is $2 \mathrm{~mm} /$ day. Positive values are shaded. Thick solid and thick dashed contours show a $90 \%$ confidence level. (b) Same as (a), but for water vapor flux and its convergence. The figure format is the same as in Fig. 21d. ERA-40 data are used. (c) Change of precipitation as future minus present-day climatology simulated by the $20-\mathrm{km}$ model for July. Same as Fig. 16a, but for a wider displayed region. (d) Change of the water vapor flux and its convergence as future minus present-day climatology simulated by the $20-\mathrm{km}$ model for July. Same as Fig. 21d. 
MRI-CGCM2.3 (Figs. 1e, f) resembles an El Niño-like response, although the location of a large positive anomaly over the tropics shifts more westward than that of the observed positive anomaly for the El Niño years. Figure 22 suggests the possibility that the change in the precipitation, the water vapor flux, and the convergence of the water vapor flux, can be interpreted as an atmospheric response to the El Niño condition of the ocean.

It has been well-known by long-range forecasters of the JMA (Ueno et al. 2001) that, under the El Niño condition, the total precipitation during the Baiu season tends to increase in association with the delay of the termination of the Baiu season. This tendency is similar to the future change obtained from the present study, suggesting that the response of the Baiu rain band observed under the El Niño condition, will be enhanced in future warmer climates.

The analyses shown in Fig. 21 have revealed that the change in the water vapor flux is a key factor to the change in the Baiu rain band. Figure 23 evaluates the relative contribution of water vapor and wind, to the change in the water vapor flux in July at $850 \mathrm{hPa}$. In the panel (b), the future vapor flux was calculated using the wind field of the present-day climatology, with the water vapor of the future climatology. Then, the present-day climatology (a) was subtracted from the calculated future vapor flux. On the other hand, in panel (c), the future vapor flux was calculated using the wind field of the future climatology, with the water vapor of the present-day climatology. Then, the presentday climatology (a) was subtracted from the calculated future vapor flux. The close similarity between panels (c) and (d) indicates that the change in the wind field mainly contributes to the change in the water vapor flux. The calculations for panels (b) and (d) were based on the monthly mean wind and water vapor, because output with a higher time resolution, such as 6-houtly or daily data, was not archived due to storage capacity limitations. This means that the contributions from higher frequencies are neglected in the calculation.

To compare the situation for the case of the Indian summer monsoon, the same calculation was conducted over the Arabian Sea and the Indian Subcontinent (figure not shown). In marked contrast to the East Asian case (Fig. 22 ), the increase of the water vapor mainly contributes to the increase of the water vapor flux of the Somali jet. This is consistent with the results by Kitoh et al. (1997).

An observational study by $\mathrm{Hu}$ et al. (2003) has demonstrated a conspicuous summertime precipitation trend for the period from 1951 to 2000 , which is characterized by a negative (drying) trend to the north of the Yangtze River valley, and a positive (wetting) trend over the Yangtze River valley, known as the "Northdrying south-wetting pattern". Moreover, Hirota et al. (2005) has investigated the observed summertime precipitation trend over East Asia from 1979 to 2003 . They found that the precipitation significantly decreases around northeastern China, and increases over southeastern China and Japan. Our future projection has revealed that precipitation increases significantly over the Yangtze River valley, and tends to decrease in some regions in northern China (Figs. $15 \mathrm{a}$ and 16a). This suggests that the observed North-drying south-wetting pattern over China will be enhanced in a future warmer climate.

\section{Summary}

A global warming projection was conducted on the Earth Simulator using a very high horizontal resolution atmospheric general circulation model, with a $20-\mathrm{km}$ grid size. Such high horizontal resolution in a global climate model is unprecedented for a global warming projection. Experiments using the $20-\mathrm{km}$ global model were conducted by adopting the timeslice method, in which future change in the SST were predicted by an AOGCM called MRICGCM2.3 (a 270-km grid atmosphere). The IPCC SRES A1B emission scenario was assumed in the experiment.

The model reproduces a realistic Baiu rain band, or Baiu season under the present-day climate conditions in terms of the geographic distribution of precipitation, northward seasonal march of the Baiu rain band, onset and withdrawal of the Baiu season, precipitation intensity, and geographic distribution of MSLP. Experiments on the horizontal resolution dependency on the reproducibility of the Baiu rain band, have revealed that the $20-\mathrm{km}$ model generally exhibits higher performance than lower horizontal resolution models. The future 

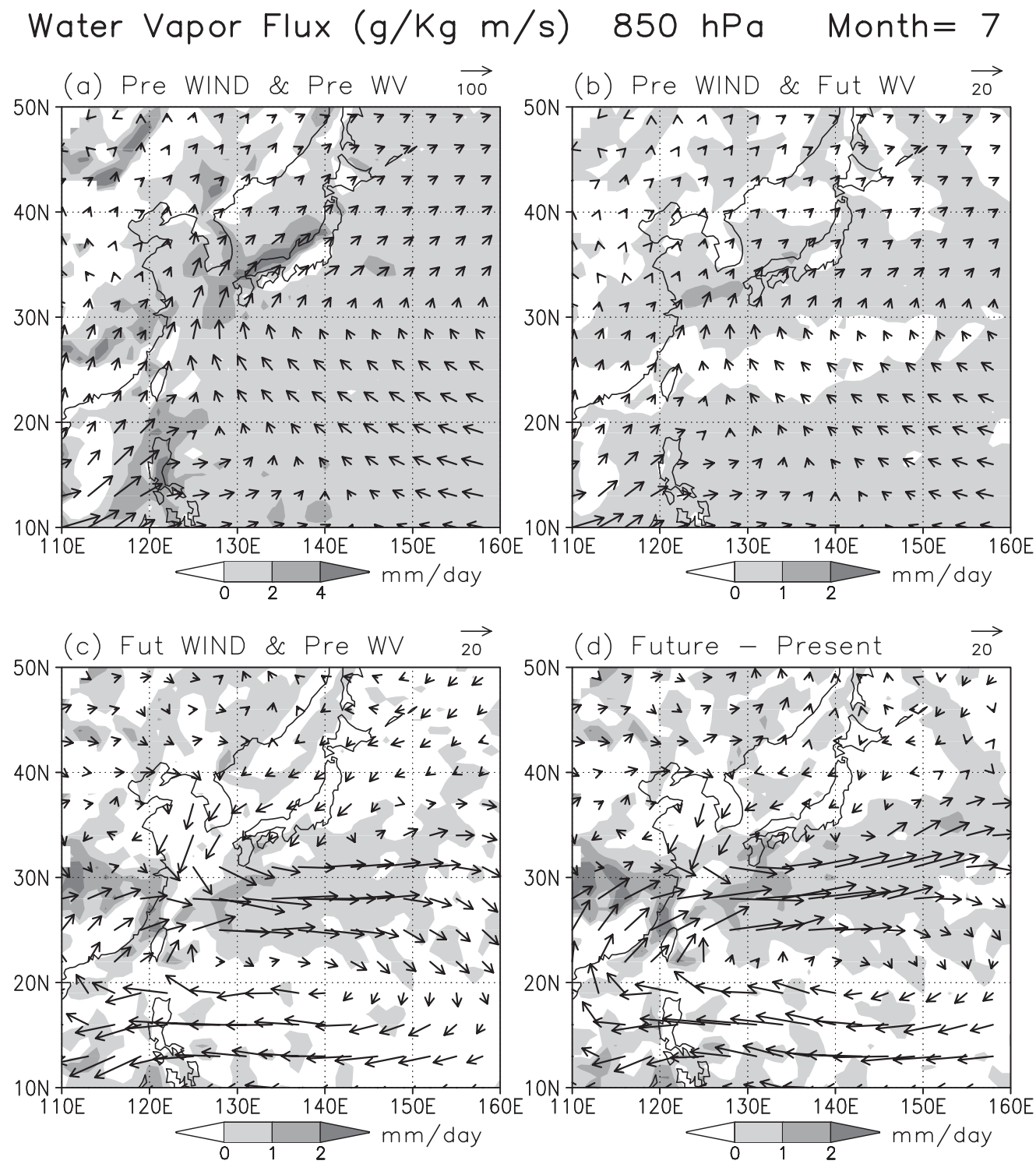

Fig. 23. Contribution of the water vapor change and wind change to the water vapor flux change of July at the $850 \mathrm{hPa}$ level. The unit is $\mathrm{g} \mathrm{Kg}^{-1} \mathrm{~m} \mathrm{~s}^{-1}$. Shading shows convergence $\left(\mathrm{mm} \mathrm{day}^{-1}\right)$. (a) Present-day water vapor flux and its convergence climatology of the 20-km model. (b) Water vapor flux change from the present-day climatology (a) using present-day climatological wind and future climatological water vapor. (c) Water vapor flux change from present-day climatology (a) using future climatological wind and present-day climatological water vapor. (d) Change of the future water vapor flux from the present-day climatology (a) using future climatology for both wind and water vapor.

climate simulation shows that precipitation and its intensity increase over the Yangtze River valley of China, the East China Sea, Western Japan, and the ocean to the south of the Japan archipelago. Conversely, precipitation, and its intensity, decrease over the Ko- rean peninsula and Northern Japan. The termination of the Baiu season tends to be delayed until August.

The future precipitation change is mainly attributable to the change in the horizontal transport of the water vapor flux, and its con- 
vergence associated with the intensification of a subtropical high, which can be interpreted as an atmospheric response to the El Niño condition of the ocean. This is plausible because the spatial structure of the future SST change forcing the $20-\mathrm{km}$ model, resembles an El Niño-like response. The analyses indicate that the change in the wind field contributes to the change in the water vapor flux, in the case of the Baiu rain band.

\section{Acknowledgements}

This study was conducted under the framework of the Research Revolution 2002 (RR2002) project "Development of Super-High-Resolution Global and Regional Climate Models", funded by the Ministry of Education, Culture, Sports, Science and Technology (MEXT). This project is called "Kyosei-4 project". We thank Drs. T. Matsuo and T. Aoki and members of the Kyosei-4 global modeling subgroup (in alphabetical order): M. Hosaka, H. Ishizaki, A. Kitoh, M. Mikami, H. Tsujino, T. Shibata, T. Uchiyama, T. Yasuda, and S. Yukimoto (Meteorological Research Institute, MRI), M. Hirai, T. Hosomi, T. Kadowaki, K. Katayama, H. Kawai, M. Kazumori, H. Kitagawa, C. Kobayashi, M. Kyoda, S. Maeda, T. Matsumura, S. Murai, M. Nakagawa, A. Narui, T. Ose, R. Sakai, T. Sakashita, Y. Takeuchi, K. Yamada, and M. Yamaguchi (Japan Meteorological Agency, JMA), K. Fukuda, K. Horiuchi, K. Miyamoto, and H. Murakami (Advanced Earth Science \& Technology Organization, AESTO). Thanks are also extended to anonymous reviewers whose valuable comments and suggestions greatly improved the manuscript. The advice from Dr. S. Manabe was also very helpful. We appreciate Dr. T. Nakaegawa for providing us the vertically integrated observed water vapor flux based on 6hourly ERA-40 data.

\section{Appendix}

Taylor (2001) devised a diagram to quantify how well models simulate an observed climate field. This diagram is called the "Taylor diagram" and was adopted to evaluate the performance of climate models in Chapter 8 (Model Evaluation) of IPCC (2001).

The root-mean-square (RMS) difference $E$ between the observation and the model is defined as:

$$
E=\sqrt{\frac{1}{N} \sum_{n=1}^{N}\left(f_{n}-r_{n}\right)^{2}},
$$

where $f$ is the target variable of model, $r$ is a reference variable such as an observation, $n$ is the sample number in space and/or time, and $N$ is the total number of samples. The square of the RMS difference $E$ can be decomposed into two terms:

$$
E^{2}=\bar{E}^{2}+E^{\prime 2}
$$

where the bias $\bar{E}$ is defined as

$$
\bar{E}=\bar{f}-\bar{r},
$$

the centered pattern RMS difference $E^{\prime}$ is defined as

$$
E^{\prime}=\sqrt{\frac{1}{N} \sum_{n=1}^{N}\left[\left(f_{n}-\bar{f}\right)-\left(r_{n}-\bar{r}\right)\right]^{2}},
$$

$\bar{f}$ is the mean of $f$ and $\bar{r}$ is the mean of $r$. The centered pattern RMS difference $E^{\prime}$ can be regarded as bias corrected RMS difference. Denoting the standard deviation of $f$ as $\sigma_{f}$, the standard deviation of $r$ as $\sigma_{r}$, and the correlation coefficient between $f$ and $r$ as $R$, the four statistical quantities of interest satisfy the following equation:

$$
E^{\prime 2}=\sigma_{f}^{2}+\sigma_{r}^{2}-2 \sigma_{f} \sigma_{r} R .
$$

The similarity of the above equation to the law of cosine makes it possible to display the geometric relationship among $E^{\prime}, \sigma_{f}, \sigma_{r}$, and $R$ as shown in Fig. A. The model field is positioned such that $\sigma_{f}$ is the radial distance from the origin, $R$ is the cosine of the azimuthal angle, and $E^{\prime}$ is the distance to the observed point. In the limit of perfect simulation by the model, the model point coincides with the observed point, which means that $E^{\prime}$ approaches zero and $R$ approaches unity. In panel (b) of Figs. 4, 5, 9, 13 and 14 , the centered pattern RMS difference $E^{\prime}$ and all standard deviations are normalized by the corresponding observed standard deviation $\sigma_{r}$. Because the observed standard deviation $\sigma_{r}$ is also normalized by itself, the observed point will therefore always be plotted at unit distance from the origin along the abscissa.

Taylor (2001) has also proposed a skill score $S$ evaluating both the standard deviation and correlation coefficient: 


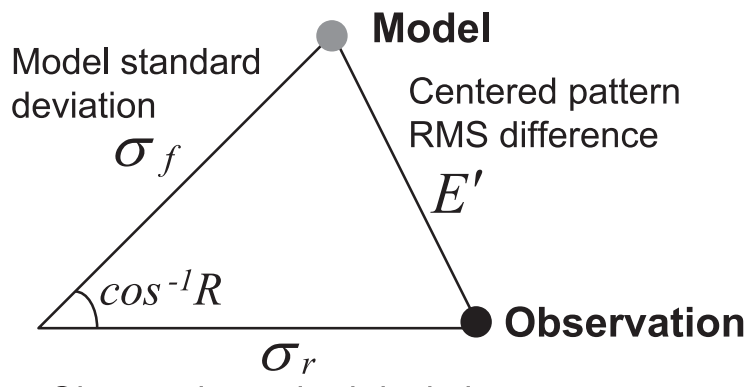

Observed standard deviation

Fig. A. Geometric relationship among the centered pattern root-mean-square (RMS) difference $E^{\prime}$, the standard deviation of model $\sigma_{f}$, the standard deviation of observation $\sigma_{r}$. and the correlation coefficient $R$ between the model and the observation. From Taylor (2001).

$$
S=\frac{4(1+R)}{\left(\hat{\sigma}_{f}+1 / \hat{\sigma}_{f}\right)^{2}\left(1+R_{0}\right)},
$$

where $\hat{\sigma}_{f}=\sigma_{f} / \sigma_{r}$ and $R_{0}$ is the maximum correlation attainable. $S$ approaches unity in the case of perfect simulation (the position of observation). Taylor (2001) estimated $R_{0}$ as 0.9976 by the intra-ensemble correlation coefficients based on six-member ensemble simulations. In the present study we have assumed $R_{0}$ as unity because an ensemble simulation was not available. However, the differences of the $S$ values are negligible, and the contour lines of $S$ for $R_{0}=0.9976$ and 1.0 are indistinguishable in the panel (b) of Figs. 4, 5, 9, 13, and 14.

\section{References}

Adler, R.F., G.J. Huffman, A. Chang, R. Ferrano, P.-P. Xie, J. Janowiak, B. Rudolf, U. Schneider, S. Curtis, D. Bolvin, A. Gruber, J. Susskind, P. Arkin, and E. Nelkin, 2003: The Version-2 Global Precipitation Climatology Preject (GPCP) Monthly Precipitation Analysis (1979Present). J. Hydrometeor., 4, 1147-1167.

Bengtsson, L., M. Botzet, and M. Esch, 1996: Will greenhouse gas-induced warming over the next 50 years lead to higher frequency and greater intensity of hurricanes? Tellus, 48A, 57-73.

Frich, P., L.V. Alexander1, P. Della-Marta, B. Gleason, M. Haylock, A.M.G. Klein Tank, and T. Peterson, 2002: Observed coherent changes in climatic extremes during the second half of the twentieth century. Clim. Res., 19, 193-212.
Giorgi, F. and R. Francisco, 2000: Evaluating uncertainties in the prediction of regional climate. Geophys. Res. Lett., 27, 1295-1298.

, P.H. Whetton, R.G. Jones, J.H. Christensen, L.O. Mearns, B. Hewitson, H. vonStorch, R. Francisco, and C. Jack, 2001: Emerging patterns of simulated regional climatic changes for the 21st century due to anthropogenic forcings. Geophys. Res. Lett., 28, 3317-3320.

Habata, S., M. Yokokawa, and S. Kitawaki, 2003: The development of the Earth Simulator. IEICE TRANSACTIONS on Information and systems. E86-D, 1947-1954.

, K. Umezawa, M. Yokokawa, and S. Kitawaki, 2004: Hardware system of the Earth Simulator. Parallel Computing, 30, 1287-1313.

Hirota, N., M. Takahashi, N. Sato, and M. Kimoto, 2005: Recent climate trends in the East Asia during the Baiu season of 1979-2003. SOLA, 1, 137-140.

$\mathrm{Hu}$, Z.-Z., S. Yang, and R. Wu, 2003: Long-term climate variations in China and global warming signals. J. Geophys. Res., 108(D19), 4614, doi:10.1029/2003JD003651.

Huffman, G.J., R.F. Adler, M.M. Morrissey, T. Bolvin, S. Curtis, R. Joyce, B. McGavock, and J. Susskind, 2001: Global precipitation at onedegree daily resolution from multi-satellite observations. J. Hydrometeor., 2, 36-50.

Hulme, M., Z.-C. Zhao, and T. Jiang, 1994: Recent and future climate change in East Asia. Intl. J. Climatol., 14, 637-658.

IPCC (Intergovernmental Panel on Climate Change), 1996: Climate Change 1995: The science of Climate Change. Contribution of Working Group I to the Second Assessment Report of the Intergovernmental Panel on Climate Change. [Houghton, J.T., L.G. Meira Filho, B.A. Callender, N. Harris, A. Kattenberg, and K. Maskell (eds.)]. Cambridge University Press, Cambridge, UK.

IPCC, 2000: Special Report on Emissions Scenarios. A Special Report of Working Group III of the Intergovernmental Panel on Climate Change. [Nakićenović, N., J. Alcamo, G. Davis, B. de Vries, J. Fenhann, S. Gaffin, K. Gregory, A. Grübler, T. Yong Jung, T. Kram, E.L. La Rovere, L. Michaelis, S. Mori, T. Morita, W. Pepper, H. Pitcher, L. Price, K. Riahi, A. Roehrl, H.-H. Rogner, A. Sankovski, M. Schlesinger, P. Shukla, S. Smith, R. Swart, S. van Rooijen, N. Victor, and Z. Dadi (eds.)]. Cambridge University Press, Cambridge, UK. , 2001: Climate Change 2001: The Scientific Basis. Contribution of Working Group I to the Third Assessment Report of the Intergovernmental Panel on Climate Change [Houghton, 
J.T., Y. Ding, D.J. Griggs, M. Noguer, P.J. van der Linden, X. Dai, K. Maskell, and C.A. Johnson (eds.)]. Cambridge University Press, Cambridge, United Kingdom and New York, NY, USA, 881pp.

Kang, I.S., K. Jin, B. Wang, K.M. Lau, J. Shukla, V. Krishnamurthy, S.D. Schubert, D.E. Wailser, W.F. Stern, A. Kitoh, G.A. Meehl, M. Kanamitsu, V.Y. Galin, V. Satyan, C.K. Park, and Y. Liu, 2002: Intercomparison of the climatological variations of Asian summer monsoon precipitation simulated by 10 GCMs. Clim. Dyn., 19, 383-395.

Kato, H.K. Nishizawa, H. Hirakuchi, S. Kadokura, N. Oshima, and F. Giorgi, 2001: Perfiormance of RegCM2.5/NCAR-CSM nested system for the simulation of climate change in East Asia caused by global warming. J. Meteor. Soc. Japan, 79, 99-121.

Kawatani, Y. and M. Takahashi, 2003: Simulation of the Baiu front in a high resolution AGCM. $J$. Meteor. Soc. Japan, 81, 113-126.

Kimoto, M., 2005: Simulated change of the east Asian circulation under global warming scenario. Geophys. Res. Lett., 32, L16701, doi:10.1029/2005GL023383.

, N. Yasutomi, C. Yokoyama, and S. Emori, 2005: Projected changes in precipitation characteristics around Japan under the global warming. SOLA, 1, 85-88.

Kitoh, A., 2006: Chapter 17, Asian monsoon in the future. In 'The Asian Monsoon', Edited by B. Wang, Springer-Verlag, 631-649.

- and T. Uchiyama, 2006: Changes in onset and withdrawal of the East Asian summer rainy season by multi-model global warming experiments. J. Meteor. Soc. Japan, 84, 247-258.

—, S. Yukimoto, A. Noda, and T. Motoi, 1997: Simulated changes in the Asian summer monsoon at times of increased atmospheric $\mathrm{CO}_{2}$. J. Meteor. Soc. Japan, 75, 1019-1031.

—, M. Hosaka, Y. Adachi, and K. Kamiguchi, 2005: Future projections of precipitation characteristics in East Asia simulated by the MRI CGCM2. Advances in Atmospheric Sciences, 22, 467-478.

Kobayashi, C. and M. Sugi, 2004: Impact of horizontal resolution on the simulation of the Asian summer monsoon and tropical cyclones in the JMA global model. Clim. Dyn., 93, 165-176.

Kurihara, K., K. Ishihara, H. Sasaki, Y. Fukuyama, H. Saitou, I. Takayabu, K. Murazaki, Y. Sato, S. Yukimoto, and A. Noda, 2005: Projection of climate change over Japan due to global warming by High-Resolution Regional Climate Model in MRI. SOLA, 1, 97-100.
Kusunoki, S., M. Sugi, A. Kitoh, C. Kobayashi, and K. Takano, 2001: Atmospheric seasonal predictability experiments by the JMA AGCM. $J$. Meteor. Soc. Japan, 79, 1183-1206.

Lau, K.-M., J.H. Kim, and Y. Sud, 1996: Intercomparison of hydrologic processes in AMIP GCMs. Bull. Amer. Meteor. Soc., 77, 2209-2227.

_ and S. Yang, 1996: Seasonal variation, abrupt transition, and intraseasonal variability associated with the Asian summer monsoon in the GLA GCM. J. Climate, 9, 965-985.

Lal, M. and H. Harasawa, 2001: Future climate change scenarios for Asia as inferred from selected coupled atmosphere-ocean global climate models. J. Meteor. Soc. Japan, 79, 219-227.

Liang, X.Z., W.C. Wang, and A.N. Samel, 2001: Biases in AMIP model simulations of the east China monsoon system. Clim. Dyn., 17, 291304.

Makihara, Y., 1996: A method for improving radar estimates of precipitation by comparing data from radars and raingauges. J. Meteor. Soc. Japan, 74, 459-480.

Min, S.-K., E.-H. Park, and W.-T. Kwon, 2004: Future projections of East Asian climate change from multi-AOGCM ensembles of IPCC SRES Scenario Simulations. J. Meteor. Soc. Japan, 82, 1187-1211.

Mizuta, R., K. Oouchi, H. Yoshimura, A. Noda, K. Katayama, S. Yukimoto, M. Hosaka, S. Kusunoki, H. Kawai, and M. Nakagawa, 2006: $20 \mathrm{~km}$-mesh global climate simulations using JMA-GSM model-Mean Climate States-. J. Meteor. Soc. Japan, 84, 165-185.

Ninomiya, K. and T. Akiyama, 1992: Multi-scale features of Baiu, the summer monsoon over Japan and the East Asia. J. Meteor. Soc. Japan, 70, 467-495.

Reynolds, R.W. and T.M. Smith, 1994: Improved global sea surface temperature analyses using optimum interpolation. J. Climate, 7, 929-948.

Simmons, A.J. and J.K. Gibson, 2000: The ERA-40 Project Plan. ERA-40 Project Report Series No. 1. European Centre for Medium-Range Weather Forecasts, March 2000.

Sperber, K.R., S. Hameed, G.L. Potter, and J.S. Boyle, 1994: Simulation of the northern summer Monsoon in the ECMWF model: Sensitivity to horizontal resolution. Mon. Wea. Rev., 122, 2461-2481.

Taylor, K.E., 2001: Summarizing multiple aspects of model performance in a single diagram. J. Geophys. Res., 106, 7183-7192.

Ueno, M., 2001: Characteristic of climate over Japan associated with El Niño. In Usage of new climatology and numerical prediction model for 
seasonal forecasting, Text book for seasonal forecasting "Kisetsu-yohou kenshuu text", Climate and Marine Department, Japan Meteorological Agency, September 2001, 15-20. In Japanese.

Wang, B. and L. Ho, 2002: Rainy season of the Asian-Pacific summer monsoon. J. Climate, 15, 386-398.

Yasunaga, K., M. Yoshizaki, Y. Wakazuki, C. Muroi, K. Kuruhara, A. Hashimoto, S. Kanada, T. Kato, S. Kusunoki, K. Oouchi, H. Yoshimura, R. Mizuta, and A. Noda, 2006: Changes in the Baiu frontal activity in the future climate simulated by super-high-resolution global and cloud-resolving regional climate models. J. Meteor. Soc. Japan, 84, 199-220.

Yoshimura, H. and T. Matsumura, 2005: A two-timelevel vertically-conservative semi-Lagrangian semiimplicit double Fourier series AGCM. CAS/JSC WGNE Research Activities in
Atmospheric and Ocean Modeling, 35, 3.2728.

Yoshizaki, M., C. Muroi, S. Kanada, Y. Wakazuki, K. Yasunaga, A. Hashimoto, T. Kato, K. kurihara, A. Noda, and S. Kusunoki, 2005: Changes of Baiu (Mei-yu) frontal activity in the global warming climate simulated by a nonhydrostatic regional model. SOLA, 1, 25-28.

Yukimoto, S., A. Noda, A. Kitoh, M. Hosaka, H. Yoshimura, T. Uchiyama, K. Shibata, O. Arakawa, and S. Kusunoki, 2006a: Present-day climate and climate sensitivity in the Meteorological Research Institute Coupled GCM version 2.3 (MRI-CGCM2.3). J. Meteor. Soc. Japan, 84, 333-363.

, - , T. Uchiyama, and S. Kusunoki, 2006b: Climate Change of the late nineteenth through twenty-first centuries simulated by the MRI-CGCM2.3. Papers in. Meteor. and Geophys., 56, 9-24. 